\title{
RESEARCH
}

Open Access

\section{Protective mechanism of artemisinin on rat bone marrow-derived mesenchymal stem cells against apoptosis induced by hydrogen peroxide via activation of c-Raf- Erk1/2-p90 ${ }^{\text {rsk }}$-CREB pathway}

Jiankang Fang ${ }^{1 \dagger}$, Xia Zhao ${ }^{1+}$, Shuai $\mathrm{Li}^{1}$, Xingan Xing ${ }^{1}$, Haitao Wang ${ }^{2}$, Philip Lazarovici ${ }^{3}$ and Wenhua Zheng ${ }^{1 *}$ (D)

\begin{abstract}
Background: Bone marrow-derived mesenchymal stem cell (BMSC) transplantation is one of the new therapeutic strategies for treating ischemic brain and heart tissues. However, the poor survival rate of transplanted BMSCs in ischemic tissue, due to high levels of reactive oxygen species (ROS), limits the therapeutic efficacy of this approach. Considering that BMSC survival may greatly enhance the effectiveness of transplantation therapy, development of effective therapeutics capable of mitigating oxidative stress-induced BMSC apoptosis is an important unmet clinical need.

Methods: BMSCs were isolated from the 4-week-old male Sprague Dawley rats by whole bone marrow adherent culturing, and the characteristics were verified by morphology, immunophenotype, adipogenic, and osteogenic differentiation potential. BMSCs were pretreated with artemisinin, and $\mathrm{H}_{2} \mathrm{O}_{2}$ was used to induce apoptosis. Cell viability was detected by MTT, FACS, LDH, and Hoechst 33342 staining assays. Mitochondrial membrane potential $(\Delta \psi \mathrm{m})$ was measured by JC-1 assay. The apoptosis was analyzed by Annexin V-FITC/PI and Caspase 3 Activity Assay kits. ROS level was evaluated by using CellROX ${ }^{\circledR}$ Deep Red Reagent. SOD, CAT, and GPx enzymatic activities were assessed separately using Cu/Zn-SOD and Mn-SOD Assay Kit with WST-8, Catalase Assay Kit, and Total Glutathione Peroxidase Assay Kit. The effects of artemisinin on protein expression of BMSCs including p-Erk1/2, t-Erk1/2, p-c-Raf, $p-p 90^{\text {rsk }}, p-C R E B, B C L-2, B a x, p-A k t, t-A k t, \beta$-actin, and GAPDH were measured by western blotting.

(Continued on next page)
\end{abstract}

\footnotetext{
* Correspondence: wenhuazheng@umac.mo

${ }^{\dagger}$ Jiankang Fang and Xia Zhao contributed equally to this work.

${ }^{1}$ Centre of Reproduction, Development and Aging, Institute of Translational

Medicine, Faculty of Health Sciences, University of Macau, Macau SAR, China

Full list of author information is available at the end of the article
}

(c) The Author(s). 2019 Open Access This article is distributed under the terms of the Creative Commons Attribution 4.0 International License (http://creativecommons.org/licenses/by/4.0/), which permits unrestricted use, distribution, and reproduction in any medium, provided you give appropriate credit to the original author(s) and the source, provide a link to the Creative Commons license, and indicate if changes were made. The Creative Commons Public Domain Dedication waiver (http://creativecommons.org/publicdomain/zero/1.0/) applies to the data made available in this article, unless otherwise stated. 
(Continued from previous page)

Results: We characterized for the first time the protective effect of artemisinin, an anti-malaria drug, using oxidative stress-induced apoptosis in vitro, in rat BMSC cultures. We found that artemisinin, at clinically relevant concentrations, improved BMSC survival by reduction of ROS production, increase of antioxidant enzyme activities including SOD, CAT, and GPx, in correlation with decreased Caspase 3 activation, lactate dehydrogenase (LDH) release and apoptosis, all induced by $\mathrm{H}_{2} \mathrm{O}_{2}$. Artemisinin significantly increased extracellular-signal-regulated kinase 1/2 (Erk1/2) phosphorylation, in a concentration- and time-dependent manner. PD98059, the specific inhibitor of the Erk1/2 pathway, blocked Erk1/2 phosphorylation and artemisinin protection. Similarly, decreased expression of Erk $1 / 2$ by siRNA attenuated the protective effect of artemisinin. Additionally, when the upstream activator KRAS was knocked down by siRNA, the protective effect of artemisinin was also blocked. These data strongly indicated the involvement of the Erk1/2 pathway. Consistent with this hypothesis, artemisinin increased the phosphorylation of Erk1/2 upstream kinases proto-oncogene c-RAF serine/threonine-protein kinase (c-Raf) and of Erk1/2 downstream targets p90 ribosomal s6 kinase (p90 rsk) and cAMP response element binding protein (CREB). In addition, we found that the expression of anti-apoptotic protein B cell lymphoma 2 protein $(B C L-2)$ was also upregulated by artemisinin.

Conclusion: These studies demonstrate the proof of concept of artemisinin therapeutic potential to improve survival in vitro of BMSCs exposed to ROS-induced apoptosis and suggest that artemisinin-mediated protection occurs via the activation of c-Raf-Erk1/2-p90 rsk - CREB signaling pathway.

Keywords: Artemisinin, Bone marrow mesenchymal stem cells, Apoptosis, ROS, Erk1/2, Raf, p90 rsk , CREB, Phosphorylation, Protection

\section{Introduction}

BMSCs are multipotent stem cells derived from the bone marrow (BM) stem cell niche. In recent years, there has been a huge interest to isolate, culture, and characterize these BMSCs due to their therapeutic potential in regenerative medicine [1]. For purposes of experimental and therapeutic use, freshly obtained BMSCs are cultured in the plastic adherent dishes, thus providing a heterogeneous population of cells which are plastic-adherent in culture and express the typical mesenchymal markers CD29, CD73, $C D 90$, and $C D 105$ but lack expression of the typical hematopoietic markers $C D 11 b, C D 14, C D 34, C D 45$, and $C D 79 \alpha$, and have the capacity to differentiate in vitro into osteoblasts, adipocytes, and chondroblasts [2, 3]. Although mesenchymal stem cells are commonly believed to adjust with oxidative stress [4-6], the biggest obstacle to their therapeutic use is their poor survival in ischemic tissue targets after engraftment [7-9]. Therefore, studies focusing on how to protect transplanted BMSCs against oxidative stress-induced apoptosis become a key issue for the success of BMSC transplantation [10]. Pathological levels of ROS generated at the ischemic site of tissue injury have been hypothesized to lead to loss of transplanted BMSCs from this site $[11,12]$. Therefore, there is great need to identify therapies that might manipulate BMSCs to reduce ROS in both the BMSCs themselves during their culture expansion production phase and upon homing to the injured tissue microenvironment, in order to promote BMSC engraftment and enhance tissue repair.

Artemisinin, a sesquiterpene endoperoxide, discovered by the pharmacist $\mathrm{Tu}$ Youyou, is a famous natural compound from Chinese medical herb Artemisia annua. The related compounds, such as artemisinic acid, dihydroartemisinin, artesunate, artemether, and arteether are all derivatives of artemisinin. During the last several years, artemisinin-based combination treatments (ACTs) became the frontline therapy for uncomplicated malaria caused by $P$. falciparum [13-15]. Moreover, several studies indicated that artemisinin and its derivatives may be beneficial in other clinical applications by conferring different activities such as anti-inflammatory [16-20], anti-viral [21], anti-microbial [22-24], anti-cancer [25-29], immunomodulatory [17, 30], anti-fungal [31], and antidiabetic $[32,33]$. Also, there are in vitro evidences indicating the protective activity of artemisinin towards oxidative stress damage [34-38]. Thus, the main goals of the present study were to examine whether artemisinin confers cytoprotection via its antioxidant properties and to clarify whether the c-Raf/Erk1/2/p90 ${ }^{\text {rsk }} /$ CREB pathway is critical in mediating artemisinin protection towards $\mathrm{H}_{2} \mathrm{O}_{2}$ oxidative stress-induced apoptosis in BMSCs.

The present study demonstrates that artemisinin can protect BMSCs from oxidative stress possibly by activating the c-Raf/Erk1/2/p90 rsk $/$ CREB pathway.

\section{Materials and methods Materials}

MEM medium was purchased from HyClone, Logan, UT, USA; 3-(4, 5-dimethylthiazol-2-yl)-2, 5-diphenyltetrazolium bromide (MTT) and Hoechst 33342 solution were bought from Molecular Probes, Eugene, OR, USA; CellROX ${ }^{\oplus}$ Deep Red Reagent was obtained from Thermo Fisher Scientific, 
Waltham, MA, USA; Anti-rat CD45 FITC (\#11-0461-80) and Anti-mouse/rat CD 90.1(Thy-1.1) FITC (\#11-0900-81) were bought from eBioscience, San Diego, CA, USA; FITC anti-mouse/rat CD29 (\#102205) was purchased from Biolegend, San Diego, CA, USA; Caspase 3 Activity Assay Kit, mitochondrial membrane potential assay kit with JC-1, and LDH Cytotoxicity Assay Kit were bought from Beyotime Biotechnology, Haimen, China; Annexin V-FITC/PI Kit was bought from Sangon Biotech, Shanghai, China; artemisinin, dimethyl sulfoxide (DMSO), Alizarin Red S, Oil Red O, $\beta$ Glycerophosphate disodium salt hydrate, insulin, and 3isobutyl-1-methylxantine were received from Sigma (St. Louis, MO, USA); ascorbic acid, dexamethasone, propidium iodide (PI), and indomethacin were purchased from Meilun Biotech Co. Ltd. (Dalian, China); BCA Protein Assay Kit, $\mathrm{Cu} / \mathrm{Zn}-\mathrm{SOD}$ and Mn-SOD Assay Kit with WST-8, Catalase Assay Kit, and Total Glutathione Peroxidase Assay Kit were obtained from Beyotime Institute of Biotechnology (Beyotime, Shanghai, China); anti-Erk1/2 (\#9102), antiphospho-Erk1/2 (\#9101), anti-phospho-p90 ${ }^{\text {rsk }}$ (\#9341), anti-phospho-c-Raf (\#9421), anti-phospho-CREB (\#9198), anti-Bcl-2 (\#4223), anti-Bax (\#2772), anti-Akt (\#9272), anti-phospho-Akt (\#9271), and anti- $\beta$-actin (\#12620) were purchased from Cell Signaling Technology (CST), Woburn, MA, USA; KRAS antibody (\#32216) was obtained from SAB, China; anti-GAPDH (sc-32233) was bought from Santa Cruz Biotechnology, Santa Cruz, CA, USA; Clarity Western ECL substrate was purchased from BioRad, Hercules, CA, USA; PD98059 and LY294002 inhibitors were obtained from Merck Millipore, Darmstadt, Germany; siMAPK1, siMAPK3, and siKRAS were purchased from Genepharma, Shanghai, China; fetal bovine serum (FBS) was obtained from GIBCO, Grand Island, NY, USA.

\section{Animals}

The 4-week-old male Sprague Dawley rats were maintained in the Animal Facility of Faculty of Health Sciences, University of Macau (Macau, China). The protocol was approved by the Animal Ethics Committee, University of Macau.

\section{BMSC isolation and characterization}

BMSC isolation and characterization was performed as previously described with minor modification [39]. Briefly, 4-week-old male Sprague Dawley rats were sacrificed by cervical dislocation, and the body was soaked in $70 \%$ ethanol alcohol for $10 \mathrm{~min}$. Afterwards, the bone marrow was separated from tibias and femurs and subsequently flushed with MEM alpha containing 10\% FBS. The bone marrow was cultured in MEM alpha medium within 10\% FBS and 1\% penicillin-streptomycin using $75-\mathrm{cm}^{2}$ tissue culture flasks. After cell growth for $24 \mathrm{~h}$, the liquid suspension was replaced with new culture medium. The adherent cells were passaged at $80 \%$ confluency, and the cells from only passage three to five were used in the experiments.

Fluorescence-activated cell sorting (FACS) was applied to quantify the level of expression of mesenchymal and hematopoietic markers [3, 40]. Cells were harvested at $80 \%$ confluency, centrifuged at $900 \mathrm{rpm}$ for $10 \mathrm{~min}$, supernatant discarded, and cell pellets were resuspended in 3 mL FACS buffer (99\% PBS, 1\% FBS). Thereafter, the cells at a concentration of $1 \times 10^{6} / \mathrm{mL}$ were incubated with anti-rat CD 45 FITC, anti-Mouse/Rat CD 90.1 (Thy-1.1) FITC or anti-mouse/rat CD $29 \mathrm{FITC}$ at $4{ }^{\circ} \mathrm{C}$ for $30 \mathrm{~min}$, respectively. The expression level of the antigen markers was analyzed through a BD FACSCalibur (BD Biosciences, San Jose, CA). Collected data were analyzed by the software FlowJo 7.6 (Tree Star, Ashland OR, USA).

BMSCs were also identified by investigating the differentiation potential towards osteocytes and adipocytes [41]. For osteogenic differentiation, cells were seeded in 12 -well plates at a density of $4 \times 10^{4} / \mathrm{mL}$. The culture medium was replaced with osteogenic differentiation medium consisting of DMEM, 10\% FBS, $1 \%$ penicillinstreptomycin, $1 \%$ L-glutamin, $0.1 \mu \mathrm{M}$ dexamethasone, $50 \mu \mathrm{M}$ ascorbic acid, and $10 \mathrm{mM}$ glycerol 2-phosphate (BGP) once the cells were approximately $60 \%$ confluent. The medium was changed every 3 days. After 21-day culture, cells were gently washed in PBS twice followed by fixation with $4 \%$ paraformaldehyde for $20 \mathrm{~min}$ at room temperature. Then, cells were stained with $2 \%$ Alizarin Red $\mathrm{S}$ staining solution for $25 \mathrm{~min}$ at room temperature to identify the $\mathrm{Ca}^{2+}$ deposits. For adipogenic differentiation, cells were seeded in 12 -well plates at a density of $3 \times 10^{4} / \mathrm{mL}$. The culture medium was replaced with adipogenic differentiation medium consisting of DMEM, supplemented with 10\% FBS, 1\% penicillinstreptomycin, $1 \%$ L-glutamin, $1 \mu \mathrm{M}$ dexamethasone, 0.5 $\mathrm{mM}$ 3-isobutyl-1-methylxantine (IBMX), $10 \mu \mathrm{g} / \mathrm{mL}$ insulin, and $100 \mu \mathrm{M}$ indomethacin once the cells were approximately $80 \%$ confluent. Fresh medium was changed every 3 days. After 21-day culture, cells were washed with PBS twice and fixed with 4\% paraformaldehyde for $20 \mathrm{~min}$ at room temperature. Four percent paraformaldehyde was washed with PBS twice followed by being stained with Oil Red $\mathrm{O}$ solution for $15 \mathrm{~min}$ at room temperature to identify the lipid droplets.

\section{Assessment of cytotoxicity using MTT assay}

The cytotoxicity was analyzed using MTT assay as described [42], with minor modification. Briefly, BMSCs were plated into 96 wells at a density of $5 \times 10^{4} / \mathrm{mL}$. For detecting the cytotoxicity of artemisinin or $\mathrm{H}_{2} \mathrm{O}_{2}$, BMSCs were incubated with artemisinin (0.1-100 $\mu \mathrm{M})$ or $\mathrm{H}_{2} \mathrm{O}_{2}(25-800 \mu \mathrm{M})$ in serum-free medium for $24 \mathrm{~h}$, followed by the addition of $10 \mu \mathrm{L}$ MTT $(0.5 \mathrm{mg} / \mathrm{mL})$ into each well. After 2 -h incubation, medium was discarded 
and $100 \mu \mathrm{L}$ DMSO was added in each well. The plate was shaken for $10 \mathrm{~min}$, and then, the optical density (OD) values were read at a wavelength of $570 \mathrm{~nm}$ using Infinite M200 PRO Multimode Microplate Reader (Tecan, Männedorf, Switzerland). The viability of living cells was calculated as percentage of control.

\section{Analysis of cell viability using FACS}

FACS was applied to quantify the cell viability of BMSCs by PI staining as described [43], with minor modification. Briefly, BMSCs were plated into 12-well plates at a density of $1 \times 10^{5} / \mathrm{mL}$. After appropriate treatment, cells were harvested and washed twice with PBS. Cells were resuspended with the binding buffer into FACS tubes at a density of $2 \times 10^{5} / \mathrm{mL}$. PI at the final concentration of $2 \mu \mathrm{g} / \mathrm{mL}$ was added into the resuspended cells followed by incubation $15 \mathrm{~min}$ on ice in the dark. The PI fluorescence was determined with BD FACSCalibur using the FL-2 channel. Collected data were analyzed by the software FlowJo 7.6.

\section{Measurement of cell viability using LDH release assay} $\mathrm{LDH}$ is a cytosolic enzyme present in the cell cytoplasm compartment and released into the extracellular space when the plasma membrane is damaged. Therefore, the $\mathrm{LDH}$ level is considered as an indicator of cell damage and can be quantified by the enzymatic reaction [44] measuring necrotic cell death [45]. Briefly, BMSCs were plated into 96 wells $\left(5 \times 10^{4}\right.$ cells $\left./ \mathrm{mL}\right)$ and incubated for $24 \mathrm{~h}$. After appropriate treatments, the supernatant was collected for LDH measurement at $560 / 590 \mathrm{~nm}$ using Infinite M200 PRO Multimode Microplate Reader according to the instructions of LDH Cytotoxicity Assay Kit. The percentage of $\mathrm{LDH}$ release (\%) was calculated compared to control untreated group.

\section{Measurement of cell viability using Hoechst 33342 staining}

Hoechst 33342 staining assay labels nuclear DNA and allows visualization of the nucleus in the interphase and chromosomes in the mitotic living cells. To analyze living BMSCs cells, Hoechst 33342 staining assay was employed [46]. In brief, BMSCs were plated into 24 wells $\left(2.5 \times 10^{4}\right.$ cells/well $)$. After treatments, cells were fixed in $4 \%$ formaldehyde for $20 \mathrm{~min}\left(25^{\circ} \mathrm{C}\right)$. Subsequently, $5 \mu \mathrm{g} /$ $\mathrm{mL}$ Hoechst 33342 dye solution $(50 \mu \mathrm{l} /$ well $)$ was used to stain cells for $10 \mathrm{~min}$. After two washings, the nuclei of BMSCs were visualized by EVOS FL Imaging System (Thermo Fisher Scientific, Waltham, MA, USA). Apoptotic dying cells were identified as the cells with blue fragmented, condensed nuclei, and the percentage of apoptotic BMSCs was calculated as from total number of cell population. The percentage of apoptotic cells was analyzed by Image J software (https://imagej.nih.gov/ij/ download.html, National Institute of Health, Bethesda, MD, USA).

\section{Measurement of the mitochondrial membrane potential $(\Delta \Psi \mathrm{m})$}

JC-1 assay was performed to measure $\Delta \Psi \mathrm{m}$ as previously published [36] and using the JC-1 mitochondrial membrane potential assay kit. In short, BMSCs were plated $\left(5 \times 10^{4}\right.$ cells $\left./ \mathrm{mL}\right)$ in 6 wells and after appropriate drug treatments; the detection of $\Delta \Psi \mathrm{m}$ was carried out according the guidelines of JC-1 kit. Images were taken by using EVOS FL Imaging System. The ratio (\%) of fluorescence red/green fluorescence intensity was calculated by Image J software, and the value was calculated relative to the control group.

\section{Measurement of apoptosis using Annexin V-FITC/PI assay}

The apoptotic rates were analyzed as described [47] with slight modification, by using the FACS methodology using a protocol recommended in the Annexin V-FITC/ PI Kit. Briefly, BMSCs were plated into 6 wells $\left(2 \times 10^{5}\right.$ cells $/ \mathrm{mL})$. After the appropriate treatments, the cells were harvested and washed with the binding buffer. Then, cells were suspended in $195 \mu \mathrm{L}$ binding buffer at a cell density of $2 \times 10^{5}$ cells $/ \mathrm{mL}$, incubated with Annexin V-FITC $(10 \mu \mathrm{g} / \mathrm{mL}, 5 \mu \mathrm{L})$ and incubated at $25^{\circ} \mathrm{C}$ for 15 min in dark. At the end of incubation, BMSCs were washed with the binding buffer $(200 \mu \mathrm{L})$ and centrifuged at $1000 \mathrm{rpm}$ for $5 \mathrm{~min}$. Cells were suspended in $190 \mu \mathrm{L}$ binding buffer with $10 \mu \mathrm{L}$ PI $(20 \mu \mathrm{g} / \mathrm{mL})$. The samples were acquired in BD FACSCalibur, and the collected data were analyzed by the software FlowJo 7.6. The apoptosis rate was expressed as the percentage of Annexin V-positive cells.

\section{Measurement of apoptosis using Caspase 3 activity assay} Caspase 3 activity was measured using the Caspase 3 Activity Assay Kit [48, 49] according to manufacturer's protocol. In brief, BMSCs were plated into 6 wells $(5 \times$ $10^{4}$ cells $/ \mathrm{mL}$ ) and treated as indicated. Culture medium and adherent cells were collected and centrifuged for 5 $\min \left(4^{\circ} \mathrm{C}, 600 \mathrm{~g}\right)$. Collected cells were resuspended and incubated in the lysis buffer (supplied with the kit) on ice for $15 \mathrm{~min}$ before being centrifuged for $12 \mathrm{~min}\left(4{ }^{\circ} \mathrm{C}\right.$, $18000 \mathrm{~g}$ ). The cell lysate supernatant was collected. The final $100 \mu \mathrm{L}$ reaction mixture contained $40 \mu \mathrm{L}$ assay buffer (supplied with the kit), $50 \mu \mathrm{L}$ cell lysate supernatant, and the $10 \mu \mathrm{L}$ Caspase 3 substrate Ac-DEVD-pNA (2 $\mathrm{mM}$ ) (supplied with the kit). The mixture was incubated at $37^{\circ} \mathrm{C}$ for $120 \mathrm{~min}$, and then, Caspase 3 activity was measured at $405 \mathrm{~nm}$ using the Infinite M200 PRO Multimode Microplate Reader. The percentage of Caspase 3 activity was calculated compared to control group. 


\section{Measurement of oxidative stress}

ROS in BMSCs were evaluated by using CellROX ${ }^{\bullet}$ Deep Red Reagent as described [34]. After appropriate treatments, medium was replaced by medium with $5 \mu \mathrm{M}$ CellROX $^{\oplus}$ Deep Red reagent and the cells were incubated at $37^{\circ} \mathrm{C}$ without light for $1 \mathrm{~h}$. Then, BMSCs were washed for three times with PBS and the images of the cells were taken by the EVOS FL Imaging System at the excitation and emission wavelengths at $640 \mathrm{~nm}$ and 665 $\mathrm{nm}$ separately. Semi-quantification of the oxidative level was calculated by using the software Image $J$ and the percentage of oxidative level (\%) was calculated compared to the control group.

\section{Measurement of SOD, CAT, and GPx activities}

Superoxide dismutase (SOD), catalase (CAT), and glutathione peroxidase (GPx) enzymatic activities were determined by using $\mathrm{Cu} / \mathrm{Zn}-\mathrm{SOD}$ and $\mathrm{Mn}$-SOD Assay Kit with WST-8, Catalase Assay Kit, and Total Glutathione Peroxidase Assay Kit (Beyotime, Beijing, China) following the manufacturer's instructions. Briefly, SOD activity determination was based on the inhibition of the superoxide radical-dependent cytochrome $\mathrm{C}$ reducing measured at a wavelength of $450 \mathrm{~nm}$ using Infinite M200 PRO Multimode Microplate Reader. CAT activity determination was based on the reducing absorbance at 520 $\mathrm{nm}$ due to the ability of scavenging $\mathrm{H}_{2} \mathrm{O}_{2}$, and the enzyme activity was converted by the speed of $\mathrm{H}_{2} \mathrm{O}_{2}$ consumption based on a standard curve obtained by the scalar units testing. GPx activity was determined according to that the speed of NADPH decrease was proportional to GPx activity measured at $340 \mathrm{~nm}$ using Infinite M200 PRO Multimode Microplate Reader. Enzyme activities were expressed as a percentage of control.

\section{Western blotting}

Western blotting was performed as described [50]. In brief, cells were rinsed by PBS and lysed in the RIPA buffer at $4{ }^{\circ} \mathrm{C}$. Concentration of proteins was determined using $\mathrm{BCA}$ protein kit. The proteins were separated by polyacrylamide gel electrophoresis and electro-transferred to nitrocellulose (NC) membranes (Millipore, Billerica, MA, USA). Membranes were incubated with $3 \%(\mathrm{w} / \mathrm{v})$ bovine serum albumin (BSA) in TBST (TBS with $0.1 \%$ Tween 20) for $1 \mathrm{~h}$ at the room temperature and incubated with the corresponding primary antibodies at $4{ }^{\circ} \mathrm{C}$ for 10 h. Thereafter, the membranes were washed with TBST several times and probed at room temperature for $1 \mathrm{~h}$ with secondary antibodies conjugated with horseradish peroxidase. The membranes were washed several times with TBST to remove the unbound secondary antibodies and then visualized using Clarity Western ECL substrate, as described in the instructions of the manufacturer.
The phosphorylation of Erk1/2, c-Raf, p90 rsk, CREB, and Akt was detected by western blotting using the respective anti-phospho-antibodies. Expression of KRAS, Bcl-2, and Bax were also measured. Blots were stripped and then reprobed with anti-total Erk1/2 antibodies to assess that equal amounts of p-Erk1/2. Blots were also stripped and reprobed with anti-GAPDH or $\beta$-actin antibodies, respectively, for different approaches of normalization. The intensity of the protein bands was analyzed by the Image J software.

\section{Statistical analysis}

All experiments were performed in triplicate, and data was expressed as the mean \pm standard deviation (SD). One-way ANOVA followed by Tukey's multiple comparison was used in the statistical analysis with the aid of the software Graph Pad Prism 5.0 (Graph Pad Software Inc., USA), and the value $p<0.05$ was considered as statistically significant.

\section{Results}

Characterization of primary cultures of rat BMSCs

Primary cultured rat BMSCs were isolated from BM [51] by their adhesion to the tissue culture surfaces, consisted of a heterogeneous cell population with a dominant spindle-shaped morphology and able to generate fibroblast-like colonies (Fig. 1a). Cells were passaged when reached about $80 \%$ confluency at 9 to 11 days in culture. Adherent cells of passage three (Fig. 1b) and passage five (Fig. 1c) showed typical spindle-shaped cell morphology [52] and were therefore used in all experiments. For further evaluation of the BMSCs phenotype, the cell-surface antigens were then analyzed by FACS which confirmed the expression of typical BMSC mesenchymal characteristic markers, i.e., CD29 (99.1\% of the cell population) and CD90 (99.5\% of cell population), as well as the absence of the early hematopoietic CD45 marker (less than $0.007 \%$ of cell population expressed this marker) [53, 54].

Characterization of osteogenic differentiation was performed by the determination of $\mathrm{Ca}^{2+}$ deposits using Alizarin Red S staining. The undifferentiated BMSCs (Fig. 1e, left) were cultured in normal medium. Accumulation of $\mathrm{Ca}^{2+} \mathrm{de}-$ posits started to be observed at the 10th day and became more at the 21th day in osteogenic differentiation medium (Fig. 1e, middle). In Alizarin Red $\mathrm{S}$ staining, $\mathrm{Ca}^{2+}$ deposits were stained red (Fig. 1e, right). Characterization of adipogenic differentiation was performed by Oil Red O staining. The undifferentiated BMSCs were cultured in normal medium and did not show any adipocyte characteristics (Fig. 1f, left). After 21-day cultivation in adipogenic differentiation medium, the lipid droplets were observed (Fig. 1f, middle), and after Oil Red O staining, lipid droplets were stained red (Fig. 1f, right). 


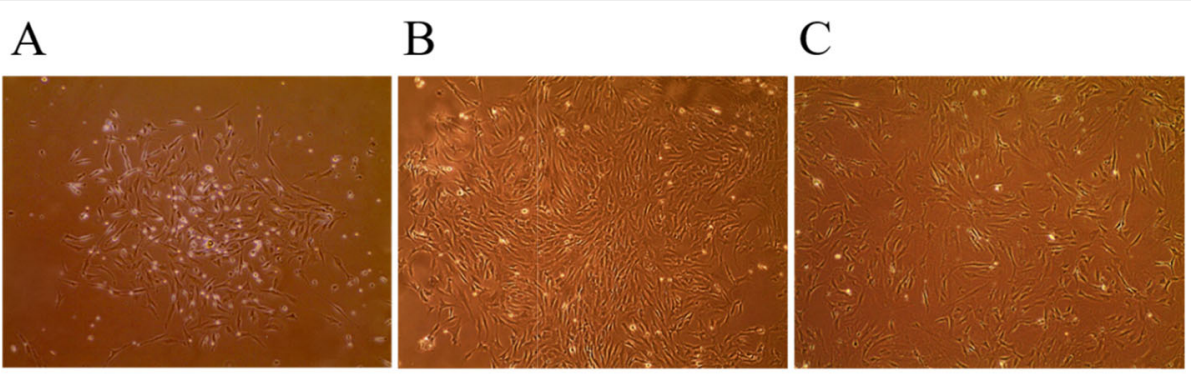

$\mathrm{D}$
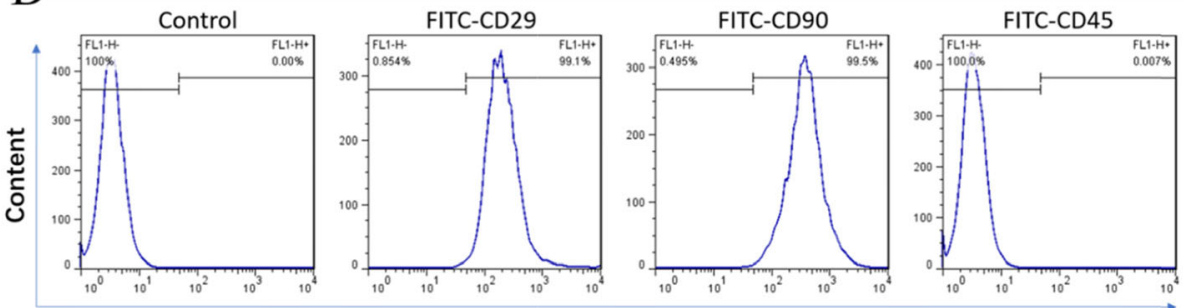

FL1-H

$\mathrm{E}$
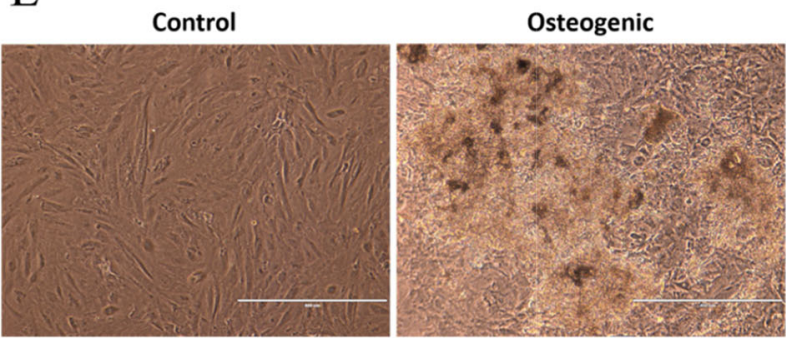

Osteogenic-ARS Staining

$\mathrm{F}$
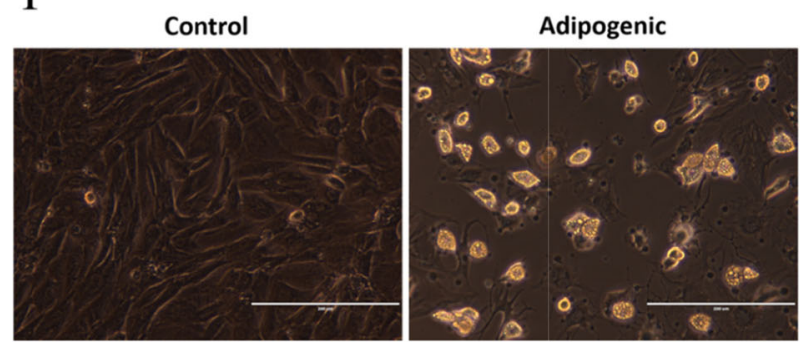

Adipogenic-ORO Staining

Fig. 1 Rat BMSC culture morphology (a-c), CD marker expression being evaluated by FACS (d), osteogenic and adipogenic differentiation induction (e, f). a The fourth day after isolation. b Passage 3. c Passage 5. d The expression levels of mesenchymal markers CD29, CD90, and hematopoietic marker CD45. e Differentiation potential to osteocytes. Cells were cultured in osteogenic differentiation medium for 21 days followed by the Alizarin Red S (ARS) staining. The representative images were presented here. Control, cultured with normal medium; osteogenic, cultured with osteogenic differentiation medium. $\mathbf{f}$ Differentiation potential to adipocytes. Cells were cultured in adipogenic differentiation medium for 21 days followed by the Oil Red $\mathrm{O}(\mathrm{ORO})$ staining. The representative images were presented here. Control, cultured with normal medium; adipogenic, cultured with adipogenic differentiation medium

\section{Artemisinin protection towards $\mathrm{H}_{2} \mathrm{O}_{2}$-induced necrotic cell death}

To investigate the protective effect of artemisinin on $\mathrm{H}_{2} \mathrm{O}_{2}$-induced cytotoxicity in BMSCs, we first analyzed the range of artemisinin concentrations which are not cytotoxic (Fig. 2a). BMSC cultures were treated with different concentrations of artemisinin $(0.1-100 \mu \mathrm{M})$, for $24 \mathrm{~h}$, and the cell viability was measured using the MTT assay. Treatment with 0.1 to $30 \mu \mathrm{M}$ was safe, while cell viability decreased by $20 \%$ upon treatment with $100 \mu \mathrm{M}$ artemisinin (Fig. 2a). Therefore, in all future experiments, the maximal concentration of artemisinin used was $30 \mu \mathrm{M}$. In the next step, to evaluate the cytotoxicity of $\mathrm{H}_{2} \mathrm{O}_{2}$, BMSCs were treated with different concentrations of $\mathrm{H}_{2} \mathrm{O}_{2}$ for $24 \mathrm{~h}$. Figure $2 \mathrm{~b}$ indicates that cell viability was decreased in a concentration-dependent 
A

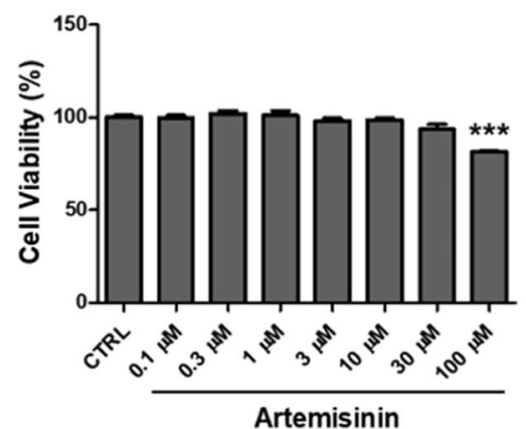

C

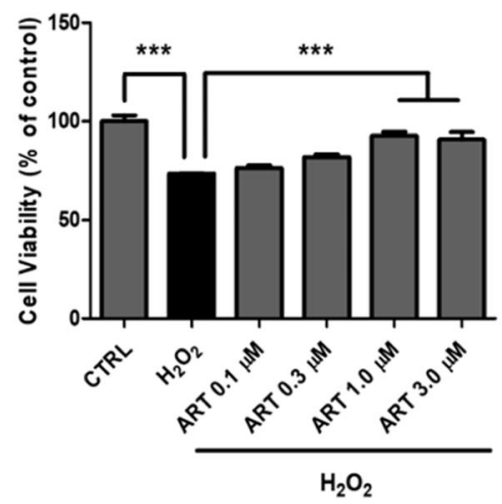

E

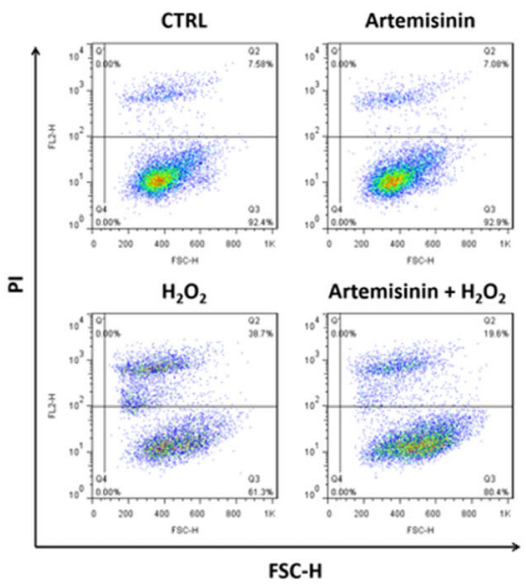

B

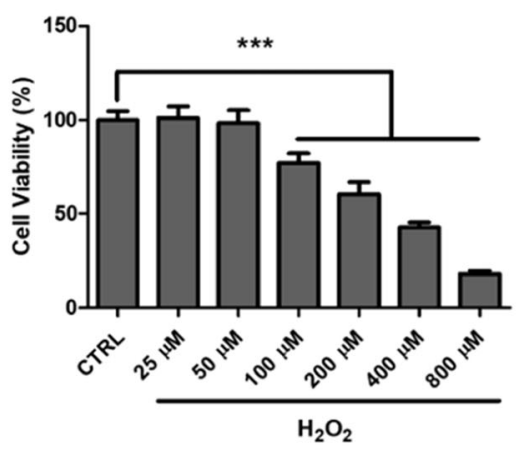

D

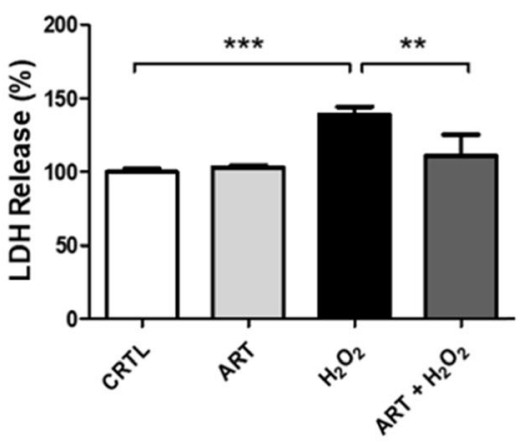

F

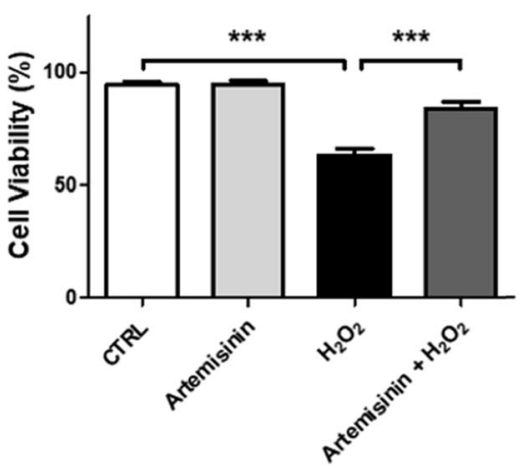

Fig. 2 Artemisinin cytoprotective effects towards $\mathrm{H}_{2} \mathrm{O}_{2}$-induced necrosis in BMSCs. a Pretreatment for $24 \mathrm{~h}$ with different concentrations of artemisinin or DMSO $(0.1 \%$, vehicle control); cell viability was measured by MTT assay $(n=3)$. b BMSCs were treated with different concentrations of $\mathrm{H}_{2} \mathrm{O}_{2}$ for $24 \mathrm{~h}$, and the cell viability was measured by MTT assay $(n=3)$. c BMSCs were pretreated with different concentrations of artemisinin (ART) or DMSO (1\%, vehicle control-CTRL) for $1 \mathrm{~h}$ before exposure to $200 \mu \mathrm{M} \mathrm{H}_{2} \mathrm{O}_{2}$ for another $24 \mathrm{~h}$; the cytotoxicity was detected by MTT assay $(n=3)$. $\mathbf{d}$ BMSCs were pretreated with $1.0 \mu \mathrm{M}$ artemisinin or DMSO $\left(0.1 \%\right.$, vehicle control) for $1 \mathrm{~h}$ and then exposed to $\mathrm{H}_{2} \mathrm{O}_{2}$ for another $24 \mathrm{~h}$; necrotic cell death was measured by LDH release $(n=3)$. e Cells were pretreated with $1.0 \mu \mathrm{M}$ artemisinin or DMSO $(0.1 \%$, vehicle control) for $1 \mathrm{~h}$ and then exposed to $200 \mu \mathrm{M} \mathrm{H}_{2} \mathrm{O}_{2}$ for another $24 \mathrm{~h}$; the cell viability was analyzed by PI staining, detected by FACS, and presented as $\%$ of the total number of cells $(\mathbf{f})(n=3)$. $\mathbf{a}, \mathbf{b}, \mathbf{f}^{* * *} p<0.005$ compared to control group; $\mathbf{c}, \mathbf{d}^{* *} p<0.01,{ }^{* *} p<0.005$. CTRL, control; ART, artemisinin; $\mathrm{H}_{2} \mathrm{O}_{2}$, exposed to hydrogen peroxide only; ART $+\mathrm{H}_{2} \mathrm{O}_{2}$, treated with artemisinin followed by exposure to hydrogen peroxide 
manner. Two hundred micromolar $\mathrm{H}_{2} \mathrm{O}_{2}$ decreased by $39.5 \%$ cell viability, and therefore, this concentration was chosen in all future experiments evaluating the potential cytoprotective effect of artemisinin.

In the next step, to investigate the protective effect of artemisinin, BMSCs pretreated with artemisinin or DMSO $(0.1 \%$, the vehicle control) at concentrations from 0.1 to $3.0 \mu \mathrm{M}$ for $1 \mathrm{~h}$ were exposed to $200 \mu \mathrm{M}$ $\mathrm{H}_{2} \mathrm{O}_{2}$ for $24 \mathrm{~h}$ and the viability was analyzed by MTT assay (Fig. 2c). Cell viability of $\mathrm{H}_{2} \mathrm{O}_{2}$ group decreased significantly compared to the control group, and artemisinin at concentrations of 1.0 and $3.0 \mu \mathrm{M}$ abrogated the $\mathrm{H}_{2} \mathrm{O}_{2}$-induced death. The cytoprotective effect of artemisinin against $\mathrm{H}_{2} \mathrm{O}_{2}$-induced death was also showed in FACS analysis using PI staining (Fig. 2e, f). In the fourth step, using the LDH assay to measure necrotic cell death (Fig. 2d), we also found that artemisinin abrogated $\mathrm{H}_{2} \mathrm{O}_{2}$-induced LDH release, confirming the cytoprotective effect measured in Fig. $2 \mathrm{c}$ and e, $\mathrm{f}$.

\section{Artemisinin protection towards $\mathrm{H}_{2} \mathrm{O}_{2}$-induced apoptotic cell death}

To further verify the cytoprotective effects of artemisinin, apoptotic cell death assays using nuclear DNA Hoechst staining observed by fluorescence microscopy to detect changes in cell nuclei and Annexin V-FITC/PI staining detected by FACS were performed. After BMSC pre-treatment with $1.0 \mu \mathrm{M}$ artemisinin for $1 \mathrm{~h}$, the number of cells with bright blue fluorescence were reduced remarkably, indicating that artemisinin can markedly decrease the number of apoptotic cells and nuclear condensation caused by $\mathrm{H}_{2} \mathrm{O}_{2}$ (Fig. 3a, b). The results of Annexin V-FITC/PI staining detected by flow cytometry revealed (Fig. 3c, d) that the $\mathrm{H}_{2} \mathrm{O}_{2}$ treatment group had a significantly higher rate of apoptosis $(32.90 \pm 4.60 \%)$ compared with the control group $(5.03 \pm 2.17 \%) \quad(P<$ $0.05)$. Treatment with artemisinin significantly protected the cells towards $\mathrm{H}_{2} \mathrm{O}_{2}$-induced apoptosis and significantly reduced the rate of apoptotic cells $(P<0.01$; $15.81 \pm 1.94 \%)$. In line with these findings, direct measurements of caspase 3 activity, presented in Fig. 3e, indicate that artemisinin $(1.0 \mu \mathrm{M})$ treatment for $1 \mathrm{~h}$ abrogated $\mathrm{H}_{2} \mathrm{O}_{2}$ activation of caspase 3 .

\section{Artemisinin protection on mitochondria}

Mitochondria in eukaryotic cells are the major components of respiration and play a critical role in the defense towards oxidative stress-induced insults. Maintaining the $\Psi \mathrm{m}$ is important to ensure the scavenging efficiency of ROS, and to confer cytoprotection towards apo-necrotic events induced by excessive ROS [55]. JC-1 is a $\Psi \mathrm{m}$ sensitive dye, aggregates in mitochondrial matrix, and exhibits a red fluorescence in the healthy cells. When $\Psi \mathrm{m}$ is reduced, JC- 1 is converted to the monomer state exhibiting a green fluorescence. Therefore, the effects of artemisinin on mitochondrial membrane potential of BMSCs were investigated using the fluorescent dye JC-1. As expected, $200 \mu \mathrm{M} \mathrm{H}_{2} \mathrm{O}_{2}$ for 24-h treatment resulted in a noticeable reduction in $\Psi \mathrm{m}$ of BMSCs, whereas artemisinin markedly increased the $\Psi \mathrm{m}$, as identified by fluorescence microscopy (Fig. 4a). In addition, the ratio of red/green fluorescence intensity was significantly decreased by $\mathrm{H}_{2} \mathrm{O}_{2}$ compared with the control group, but the effect was reversed by artemisinin (Fig. 4b). These findings suggest that artemisinin may exert beneficial effects on mitochondrial function.

\section{Artemisinin decreased the production of ROS but increased the activities of SOD, CAT, and GPx in $\mathrm{H}_{2} \mathrm{O}_{2}^{-}$ treated BMSCs}

ROS are important mediators of $\mathrm{H}_{2} \mathrm{O}_{2}$-induced cell death $[56,57]$. In order to evaluate the effect of artemisinin, on ROS levels upon $\mathrm{H}_{2} \mathrm{O}_{2}$-induced BMSC death, the cultures were pretreated with $1 \mu \mathrm{M}$ artemisinin for $1 \mathrm{~h}$ followed by exposure to $200 \mu \mathrm{M} \mathrm{H}_{2} \mathrm{O}_{2}$ for $24 \mathrm{~h}$ (Fig. 5). The data clearly indicates that intracellular ROS level significantly increased upon exposure to $\mathrm{H}_{2} \mathrm{O}_{2}$ $(276.69 \pm 17.19 \%)$ while pretreatment with artemisinin significantly attenuated the ROS production (206.61 \pm $11.86 \%$ ) induced by $\mathrm{H}_{2} \mathrm{O}_{2}$ (Fig. 5a, b). To investigate whether the antioxidant enzyme activities are mediated by artemisinin, we measured the activities of SOD, CAT, and GPx in $\mathrm{H}_{2} \mathrm{O}_{2}$-treated BMSCs. When BMSCs were treated with $200 \mathrm{uM} \mathrm{H}_{2} \mathrm{O}_{2}$, the activities of SOD, CAT, and GPx were significantly decreased compared with control, whereas treatment with artemisinin significantly increased the activities of these three enzymes compared with $\mathrm{H}_{2} \mathrm{O}_{2}$ (Fig. 5c-e).

\section{Artemisinin stimulated activation/phosphorylation of Erk $1 / 2$ is involved in the protective effect}

In previous studies we reported that the Erk $1 / 2$ signaling pathway mediate the protective effects of artemisinin in rat PC 12 dopaminergic neuronal and human retinal pigment epithelial cells [58]. We therefore sought to investigate whether this pathway was also involved in the protective effects of artemisinin in BMSCs. To verify this hypothesis, BMSCs were treated for different time periods or with various concentrations of artemisinin and culture extracts were evaluated by western blotting to measure the phosphorylation activities of Erk $1 / 2$ and Akt. The phosphorylation levels of Erk $1 / 2$ were increased by 1.5 -fold after 1 -h treatment with either 1 or $3 \mu \mathrm{M}$ artemisinin (Fig. 6a). This phosphorylation was maximal at 40-60 min and thereafter declined (Fig. 6b). By contrast, treatment with artemisinin for $1 \mathrm{~h}$, up to a concentration of $10 \mu \mathrm{M}$, did not affect Akt phosphorylation (Fig. 6c). To gain a further insight into the role of 
A
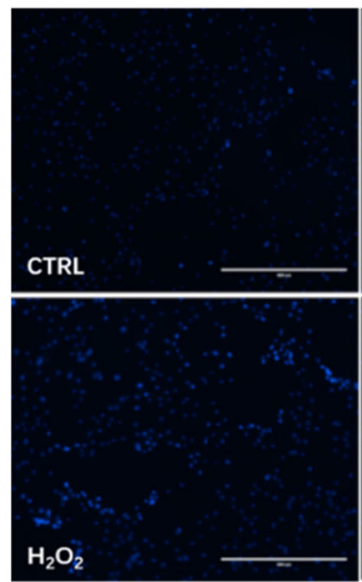

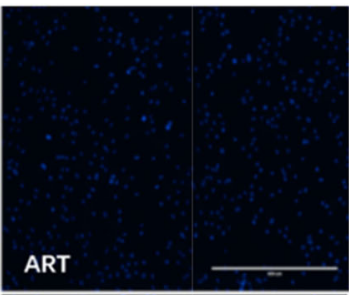

B

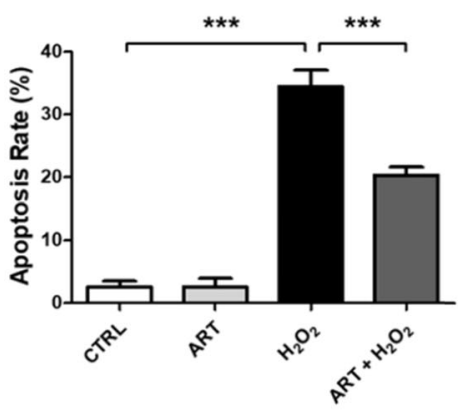

$\mathrm{C}$
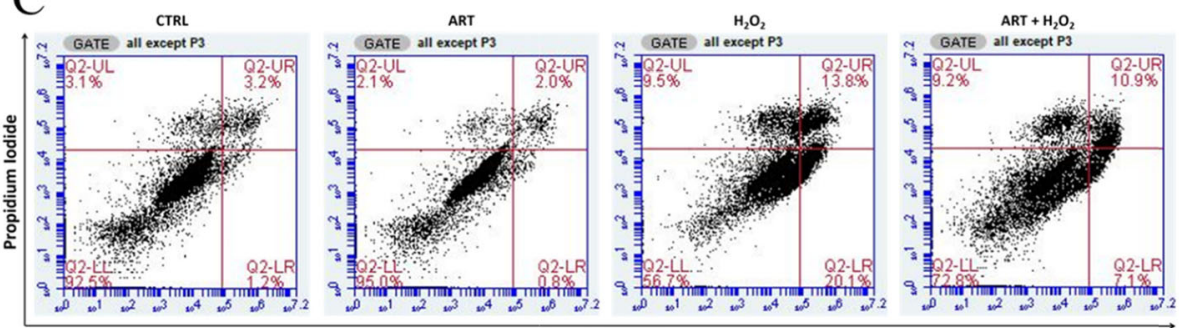

Annexin V-FITC

D

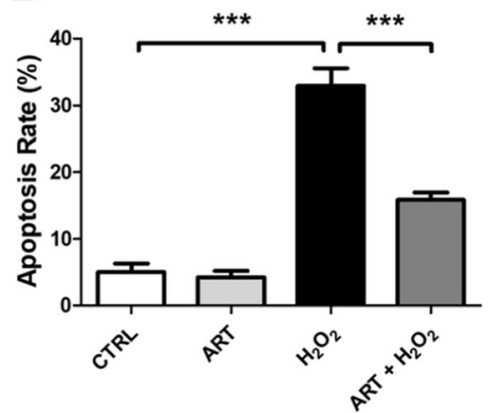

E

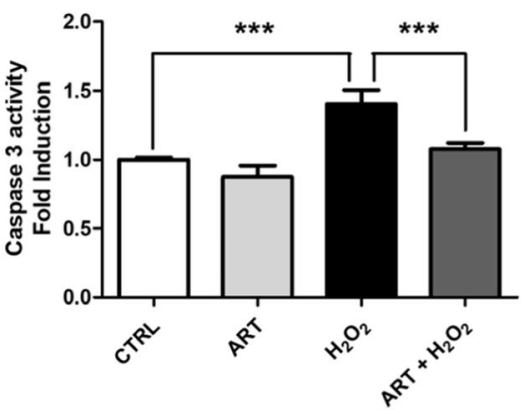

Fig. 3 Artemisinin cytoprotective effects towards $\mathrm{H}_{2} \mathrm{O}_{2}$-induced apoptosis in BMSCs. After the pretreatment with artemisinin (1.0 $\mu$ M) or DMSO (0.1\%, vehicle control) for $1 \mathrm{~h}$, BMSCs were exposed to $200 \mu \mathrm{M} \mathrm{H}_{2} \mathrm{O}_{2}$ for another $24 \mathrm{~h}$. a Cell apoptosis was measured by using nuclear DNA Hoechst staining observed by fluorescence microscopy to detect changes in cell nuclei y $(n=3)$. $\mathbf{b}$ The apoptotic and total cells were analyzed by Image J software, and the apoptosis rate was presented as \% of the total number of nuclei $(n=3)$. c The apoptotic cell death of BMSCs was analyzed by Annexin V-FITC/PI staining, detected by FACS $(n=3)$, and quantified by the apoptosis rate $(\mathbf{d})$ ( $n=3)$. e The activity of caspase 3 was measured by caspase 3 activity assay $(n=3)$. ${ }^{* *} p<0.005$. CTRL, control; ART, artemisinin; $\mathrm{H}_{2} \mathrm{O}_{2}$, exposed to hydrogen peroxide only; ART $+\mathrm{H}_{2} \mathrm{O}_{2}$, treated with artemisinin followed by exposure to hydrogen peroxide

the Erk1/2 pathway in the protective effect of artemisinin on BMSCs, the cells were preconditioned with either $10 \mu \mathrm{M}$ PD98059 (Erk1/2 inhibitor, Fig. 6d) or LY294002 (PI3K inhibitor, Fig. 6e) for $30 \mathrm{~min}$ and thereafter treated with $1.0 \mu \mathrm{M}$ artemisinin for $1 \mathrm{~h}$ followed by exposure to $200 \mu \mathrm{M}$ $\mathrm{H}_{2} \mathrm{O}_{2}$ for $24 \mathrm{~h}$, and at the end of experiment, the cell culture viability was measured using the MTT assay. The results presented in Fig. 6d, e clearly indicate that Erk1/2 but not PI3K inhibition significantly reduced artemisinin's protective effect towards $\mathrm{H}_{2} \mathrm{O}_{2}$ insult. Similarly, the silence of Erk1/2 by siMAPK1 (Erk2) and siMAPK3 (Erk1) also blocked the protective effect of artemisinin in BMSCs (Fig. 7a-d). Furtherly, the phosphorylation of Erk1/2 was significantly blocked when the upstream gene KRAS was knocked down by siKRAS, and the protection of artemisinin was also attenuated (Fig. 7e-h).

To further strength the involvement of Erk1/2 signaling pathway in artemisinin protective effect on BMSCs, 


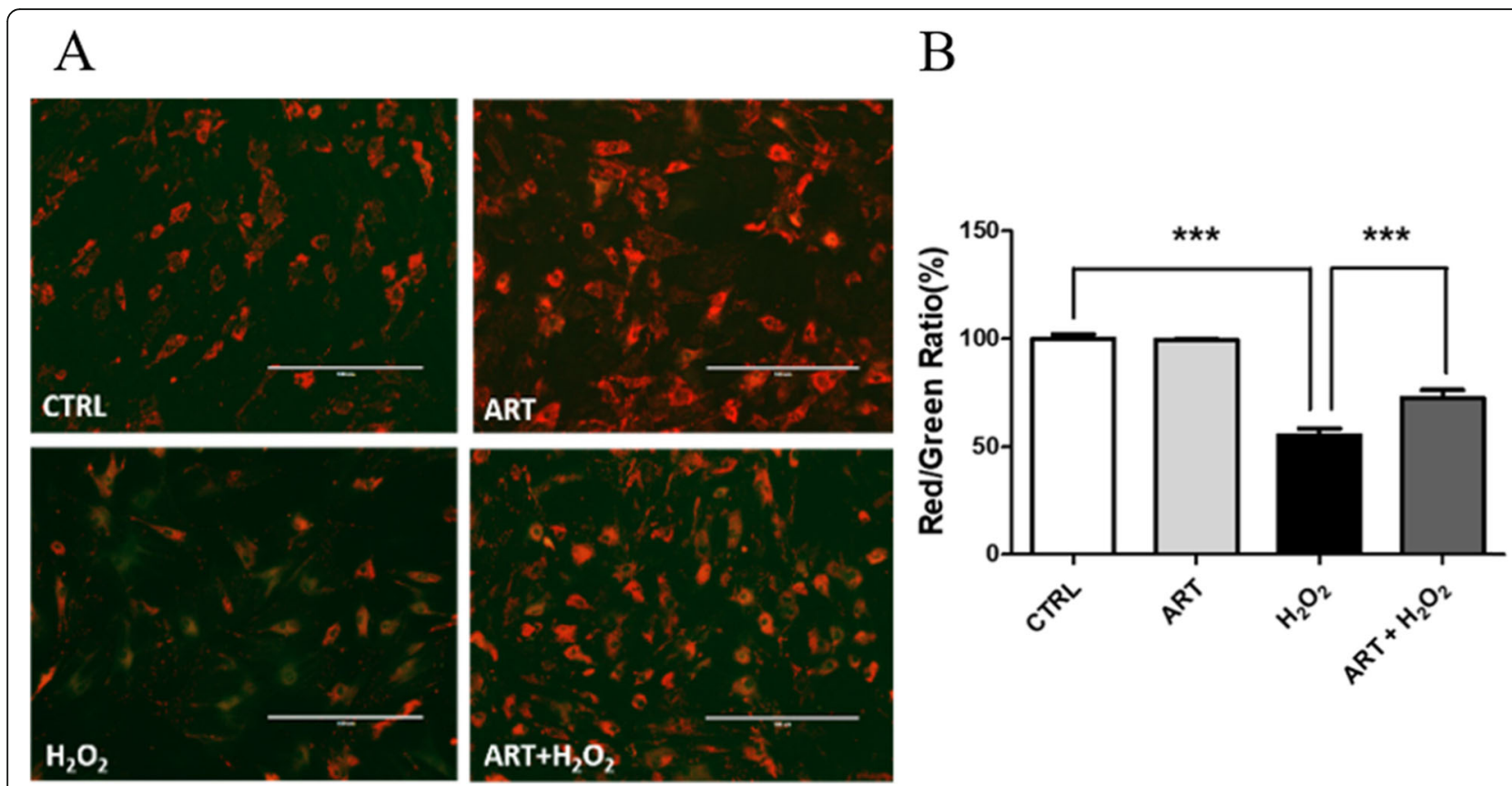

Fig. 4 Artemisinin attenuated $\mathrm{H}_{2} \mathrm{O}_{2}$-induced $\Delta \psi \mathrm{m}$ reduction. BMSCs were pretreated with $1.0 \mu \mathrm{M}$ artemisinin or DMSO $(0.1 \%$, vehicle control) for $1 \mathrm{~h}$, then exposed to $200 \mu \mathrm{M} \mathrm{H}_{2} \mathrm{O}_{2}$ for another $24 \mathrm{~h}$. a $\Delta \psi \mathrm{m}$ was analyzed using JC-1 assay $(n=3$; scale, $100 \mu \mathrm{m})$. The decline of the membrane potential was reflected by the shift of fluorescence from red to green indicated by JC-1. $\mathbf{b}$ The quantitative data of the red/green ratio $(n=3)$. ${ }^{* * *} p<0.005$. CTRL, control; ART, artemisinin; $\mathrm{H}_{2} \mathrm{O}_{2}$, exposed to hydrogen peroxide only; ART $+\mathrm{H}_{2} \mathrm{O}_{2}$, treated with artemisinin followed by exposure to hydrogen peroxide

we sought to investigate whether the phosphorylation of c-Raf (upstream of Erk1/2), p90 ${ }^{\text {RSK }}$ (downstream of Erk1/2), CREB (downstream of Erk1/2), and Bcl-2 (a typical anti-apoptotic protein) is also affected by artemisinin treatment of the cultures (Fig. 8). For this purpose, BMSCs were treated with various concentrations of artemisinin for $1 \mathrm{~h}$, and then, the culture extracts were evaluated by western blotting for phosphorylation of these proteins. At concentrations of $0.3,1$, and $3 \mu \mathrm{M}$ artemisinin, the phosphorylation of all these signaling proteins was increased by 1.2-1.7-fold compared to control (Fig. 8). Cumulatively, these results propose that c-Raf-Erk1/2-p90 RSK - CREB signaling pathway was activated by artemisinin in BMSCs.

\section{Discussion}

In the present study, we found that artemisinin protected primary cultured rat BMSCs towards $\mathrm{H}_{2} \mathrm{O}_{2}$-induced cell death. However, to the best of our knowledge, this is the first time that the antimalarial compound, artemisinin, was characterized for protective effects in insulted stem cells. Present findings suggest that activation of c-Raf-Erk1/2-p90 RSK -CREB signaling pathway was involved in the protective action of artemisinin towards oxidative stress injury. Transplantation of BMSCs becomes a potential therapy for several ischemic diseases, but the oxidative stress injury of BMSCs limits the survival of the transplanted cells and as a result failure in therapy. Present findings therefore may offer a method to protect BMSCs against oxidative stress.

At physiological levels, ROS might serve as a second messenger in the signaling pathways of proliferation and differentiation of cells in general and stem cells in particular [59]. It is also known that low-level of cellular ROS partly promotes proliferation, growth, and survival of the cells $[60,61]$. However, at pathological ROS levels, they contribute to apoptotic BMSC death and restrain their differentiation [62]. It was reported that during oxidative stress, telomere length of mesenchymal stem cells were shortened, cells underwent replicative senescence, and their differentiation abilities was decreased [63, 64]. The increase levels of ROS promoted phosphorylation of c-Jun N-terminal kinases which translocated from the cytoplasm to mitochondria resulting with caspase 3 activation followed by apoptosis [11]. Indeed, present findings (Fig. 3) support this line of research and further emphasize that artemisinin conferred protection by significantly suppressing ROS levels, increasing SOD, CAT, and GPx activities and decreasing caspase 3 activation induced in rat BMSCs exposed to $\mathrm{H}_{2} \mathrm{O}_{2}$ insult (Fig. 5). Mitochondria play a crucial role in the growth, survival, apoptosis, and some other fundamental cell functions [65]. Pretreatment of BMSCs with artemisinin significantly suppressed $\mathrm{H}_{2} \mathrm{O}_{2}$-induced collapse of $\Delta \Psi \mathrm{m}$ (Fig. 4b). 


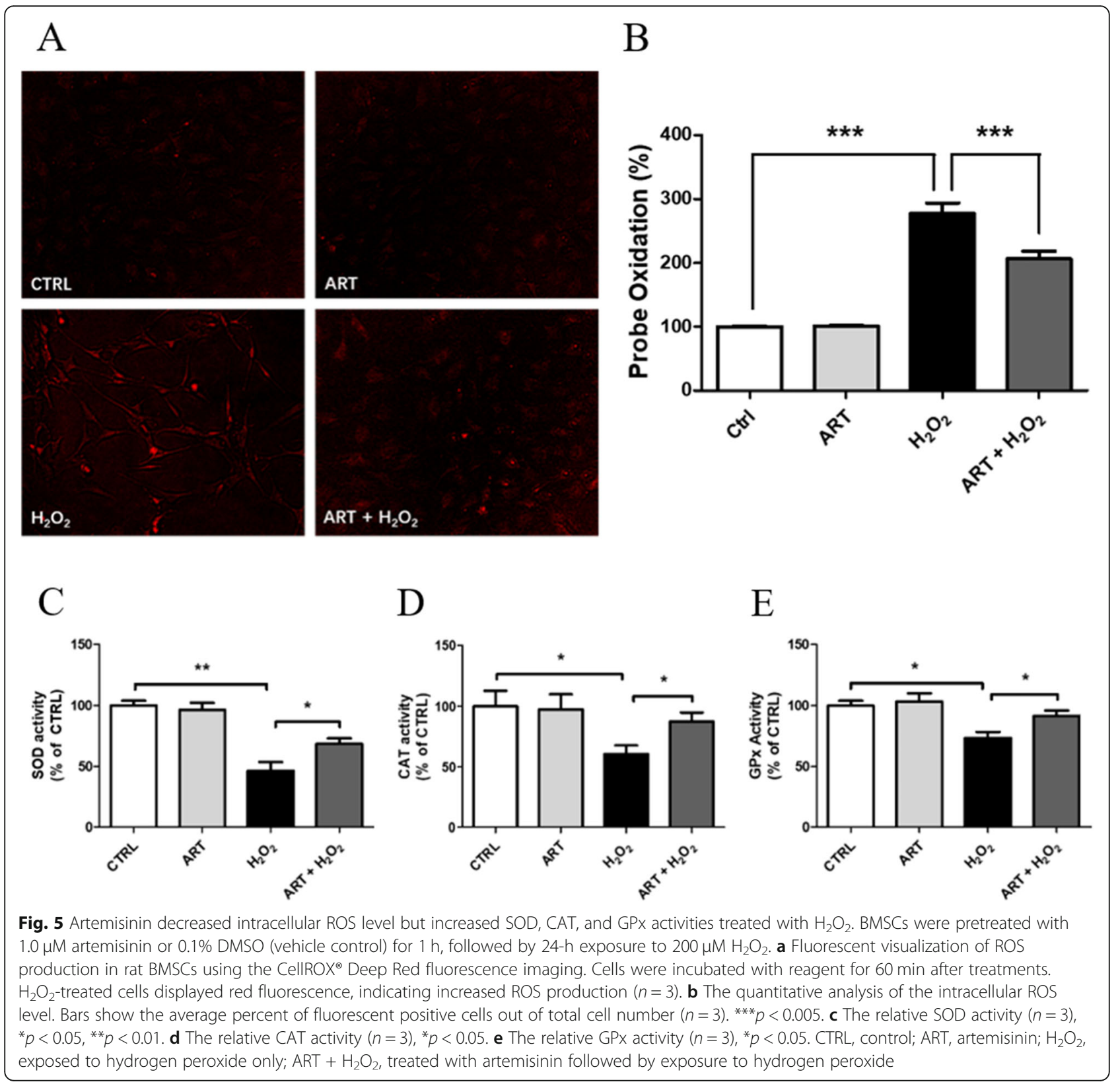

Cumulatively, these results provide circumstantial evidences on an apparent relationship between antioxidant activity, mitochondrial membrane potential stabilization, and cytoprotective effects of artemisinin.

Artemisinin pretreatment of the BMSC cultures provided efficient cytoprotection towards $\mathrm{H}_{2} \mathrm{O}_{2}$-mediated aponecrotic cell death by blocking or attenuating the increase of caspase 3 activity, LDH release, and nuclei condensation. These effects were again temporally correlated with the activation of Erk1/2. Erk1/2 can be activated by a variety of extracellular stimuli, such as serum, growth factors, and hormones regulating proliferation, apoptosis, survival, differentiation, and malignant transformation [66, 67]. Erk1/2 is a crucial signaling pathway in cell response to oxidative stress injury $[68,69]$. It was also reported that activation of Erk1/2 could correct the loss of mitochondria membrane potential in a temporal correlation with protection towards apoptotic cell death [70]. Several proposals suggest that phosphorylated and activated Erk1/2 could regulate the activity of some transcription factors, which may contribute to the protective effect [71, 72]. Artemisinin increased the phosphorylation of Erk1/2 (Fig. 6a, b) and its downstream targets $\mathrm{p} 90^{\mathrm{RSK}}$ and CREB (Fig. 8b, c) in temporal correlation with increased level of expression of Bcl-2 (Fig. 8d). And inhibition of Erk1/2 by application of Erk1/2 pathway inhibitor PD98059 and knockdown expression of Erk1/2 
A

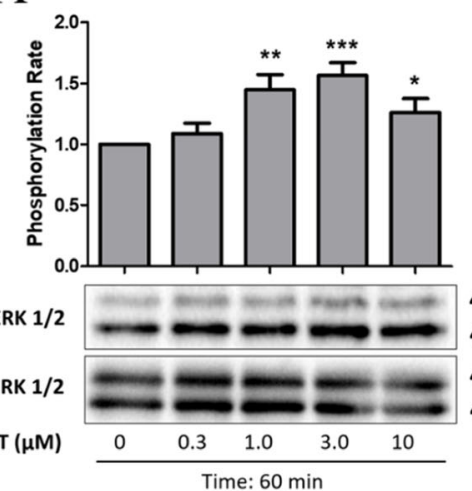

$\mathrm{C}$

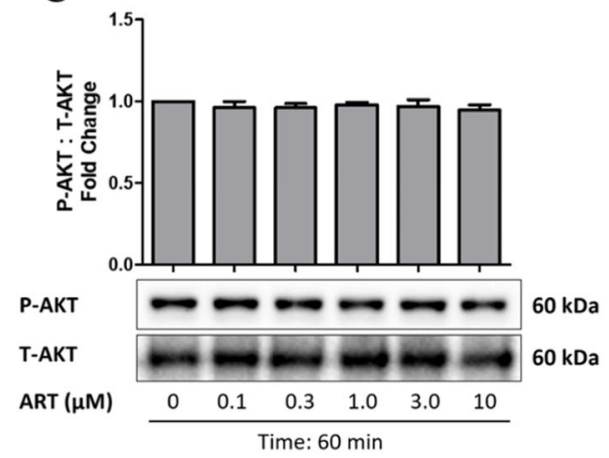

$\mathrm{E}$

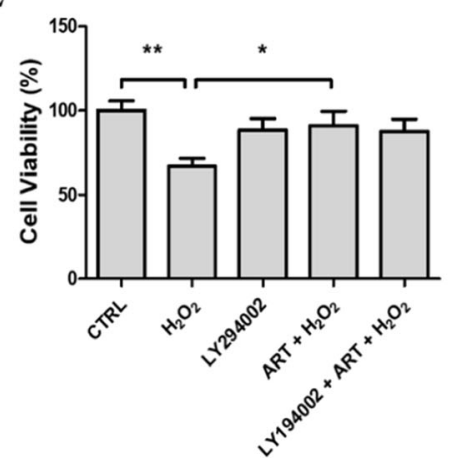

B

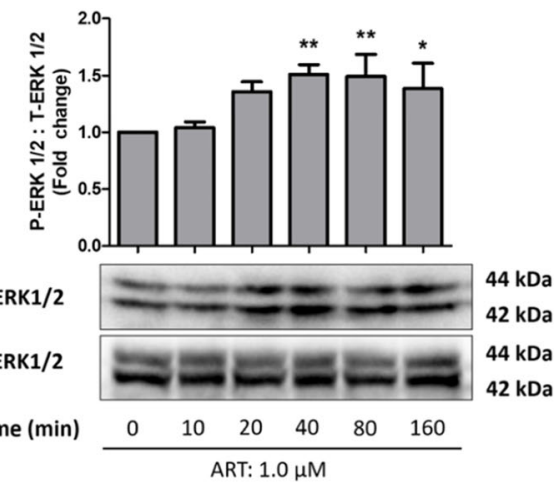

$\mathrm{D}$

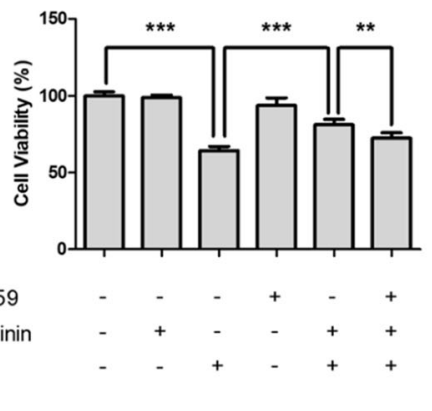

Fig. 6 Artemisinin activation of Erk1/2 but not PI3K is involved in the protective effect. a-c BMSCs were pretreated with various concentrations of artemisinin for $1 \mathrm{~h}$ or $1.0 \mu \mathrm{M}$ artemisinin for up to $160 \mathrm{~min}$. Cell lysates were submitted for western blotting to measure phosphorylation (P) and total level (T) of Erk1/2 and Akt ( $n=3)$. d, e BMSCs were preconditioned with $10 \mu \mathrm{M}$ PD98059 or LY294002 for 30 min and then treated with

$1.0 \mu \mathrm{M}$ artemisinin for $1 \mathrm{~h}$ followed by exposure to $200 \mu \mathrm{M} \mathrm{H}_{2} \mathrm{O}_{2}$ for $24 \mathrm{~h}$, and thereafter, the cell viability was determined using MTT assay ( $n=3$ ). a, ${ }^{*} p<0.05,{ }^{* *} p<0.01,{ }^{* * *} p<0.005$ versus control $(0 \mu \mathrm{M}$ in $\mathbf{a}, 0$ min in $\mathbf{b})$; d, e ${ }^{*} p<0.05,{ }^{* *} p<0.01,{ }^{* *} p<0.005$ versus control

or knockdown of upstream gene KRAS by siRNA significantly blocked the protective effect of artemisinin (Fig. 7). These results clearly indicated that the activation of Erk1/2 is involved in the protective effect of artemisinin in BMSCs.

The Bcl-2 protein family is classified into three subgroups with distinct structures: anti-apoptotic proteins like $\mathrm{Bcl}-2$ and $\mathrm{Bcl}-\mathrm{xL}$, pro-apoptotic proteins like Bax, and Bcl-2 homology 3 domain (BH3)-only proteins such as Bad [73]. The dynamic balance between anti-apoptotic
$\mathrm{Bcl}-2$ (Bcl-xL) and pro-apoptotic Bax proteins play an important role in determining the fate of cells during ischemia [74]. Accumulating evidence has shown that an increase in the ratio of $\mathrm{Bcl}-2(\mathrm{Bcl}-\mathrm{xL}) / \mathrm{Bax}$ inhibits $\mathrm{Bax}$ translocation to the mitochondria and then protects cells against apoptotic insults; however, a shift in the balance towards an excess of Bax evokes ischemia-induced apoptosis [75]. Therefore, Bcl-2 played a crucial role in the protective action against cell death induced by oxidative stress by different mechanisms including the regulation of 

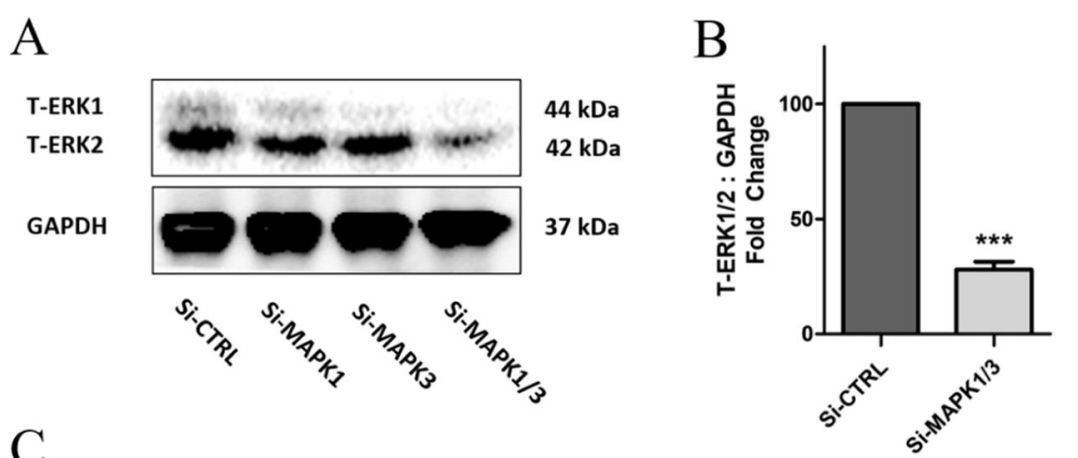

C
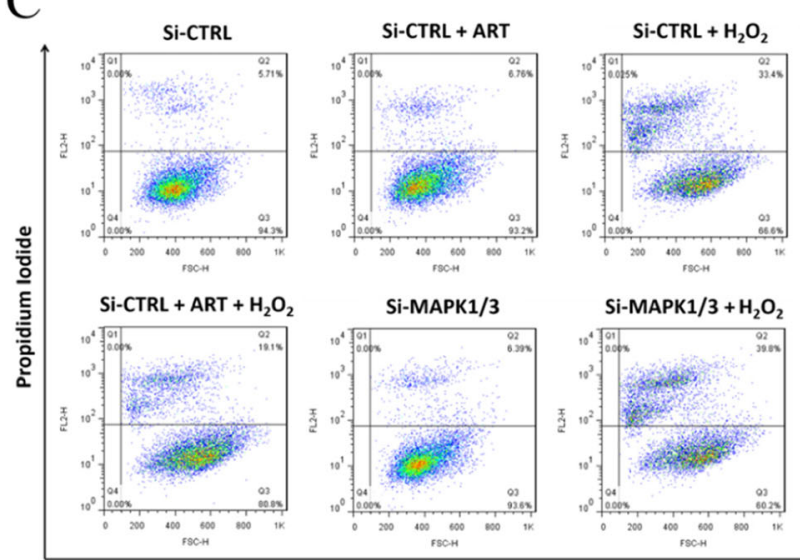

Si-MAPK1/3 + ART + $\mathrm{H}_{2} \mathrm{O}_{2}$

D

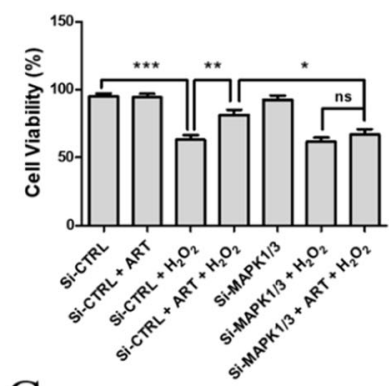

G

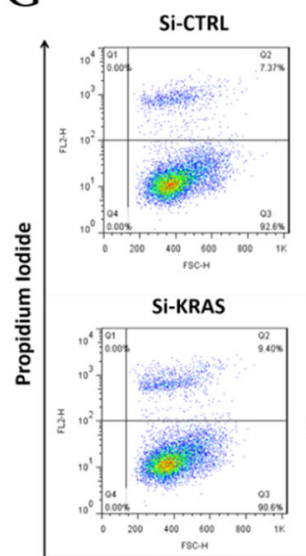

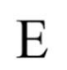

KRAS KRAS P-ERK1/2 T-ERK1/2 GAPDH

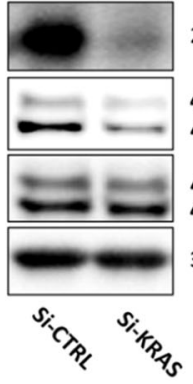

Si-CTRL $+\mathrm{H}_{2} \mathrm{O}_{2}$

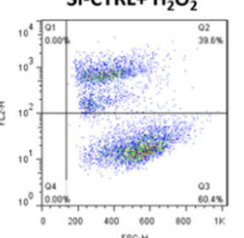

Si-KRAS $+\mathrm{H}_{2} \mathrm{O}_{2}$

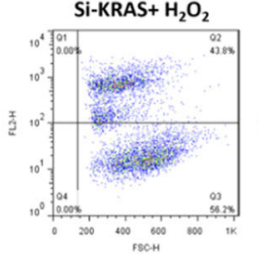

FSC-H
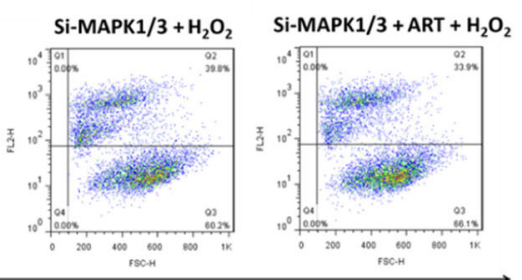

F

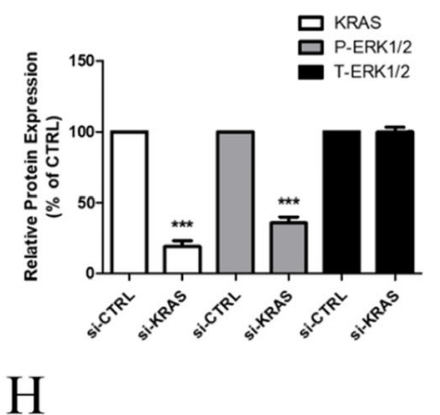

$\mathrm{Si}-\mathrm{CTRL}+\mathrm{ART}+\mathrm{H}_{2} \mathrm{O}_{2}$

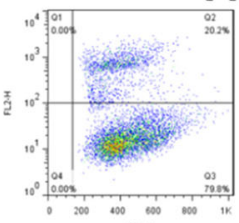

Si-KRAS+ ART $+\mathrm{H}_{2} \mathrm{O}_{2}$
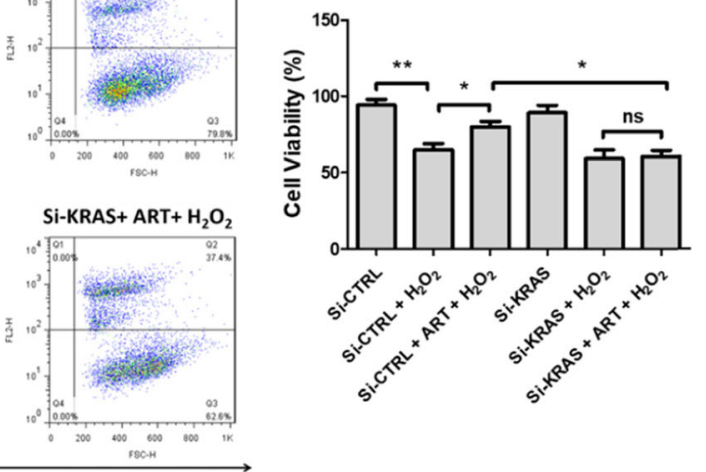

Fig. 7 (See legend on next page.) 
(See figure on previous page.)

Fig. 7 Decreased expression of Erk1/2 and KRAS by siRNA attenuated the protective effect of artemisinin. a BMSCs were transfected with $80 \mathrm{nM}$ siMAPK1 (Erk2) or with $80 \mathrm{nM}$ siMAPK3 (Erk1), or co-transfected with $80 \mathrm{nM}$ siMAPK1 and siMAPK3 for 48 h; the expression of T-Erk1, T-Erk2, and GAPDH were detected by western blotting $(n=3)$. b The quantitative analysis of T-Erk1/2 relative expression using Image J software $(n=3)$. ${ }^{* * *} p<0.005$ versus control group. c BMSCs were co-transfected with $80 \mathrm{nM}$ siMAPK1 and siMAPK3 as above and pretreated with $1.0 \mu \mathrm{M}$ artemisinin for $1 \mathrm{~h}$ followed by exposure to $200 \mu \mathrm{M} \mathrm{H}_{2} \mathrm{O}_{2}$ for another $24 \mathrm{~h}$, and the cell viability was analyzed by FACS using PI staining and quantified $(\mathbf{d})(n=3) .{ }^{*} p<0.05,{ }^{* *} p<0.01,{ }^{* * *} p<0.005$; ns, not significant. e BMSCs were transfected with $40 \mathrm{nM}$ siKRAS for $72 \mathrm{~h}$; the expressions of KRAS, p-Erk1/2, and t-Erk1/2 were detected by Western blotting. $\mathbf{f}$ The quantitative analysis of KRAS, p-Erk1/2, and t-Erk1/2 was performed using Image J software $(n=3) .{ }^{* *} p<0.005$. g The cell viability was determined by FACS using PI staining and quantified $(\mathbf{h})(n=3) .{ }^{*} p<0.05$, ${ }^{* *} p<0.01$, ns, not significant

mitochondrial bioenergetics [76-79]. In the present study, we found that artemisinin upregulated the level of expression of $\mathrm{Bcl}-2$, findings in line with the above concept, and proposing a mechanistic explanation to the protective effects of artemisinin to BMSCs exposed to $\mathrm{H}_{2} \mathrm{O}_{2}$ oxidative stress insult.

Both PI3K and Erk1/2 signaling pathways have been characterized as cellular mechanisms of anti-apoptotic and anti-oxidative stress defenses [80-85]. In present study, we did not observe any effect of artemisinin on the activation of PI3K; however, the phosphorylation of Erk1/ 2 was significantly stimulated by artemisinin pretreatment.
The protective effect was blocked when the Erk1/2 signaling pathway was inhibited by PD98059 (Fig. 6c), knockdown of the expression of Erk1/2 by siMAPK1 and siMAPK3 (Fig. 7a-d) or knockdown of the upstream gene KRAS by siKRAS (Fig. 7e-h) while the inhibitor of Akt pathway LY294002 did not affect the protective effect of artemisinin on BMSCs (Fig. 6d). These findings indicate a temporal causal correlation between the protective effects of artemisinin towards $\mathrm{H}_{2} \mathrm{O}_{2}$-induced oxidative stress and the ability of artemisinin to stimulate the phosphorylation of Erk1/2. Consistent with these findings, artemisinin stimulated phosphorylation of the downstream substrates
A
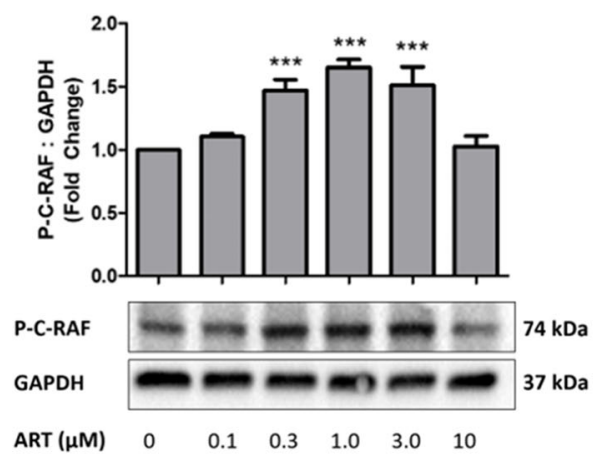

$\mathrm{C}$
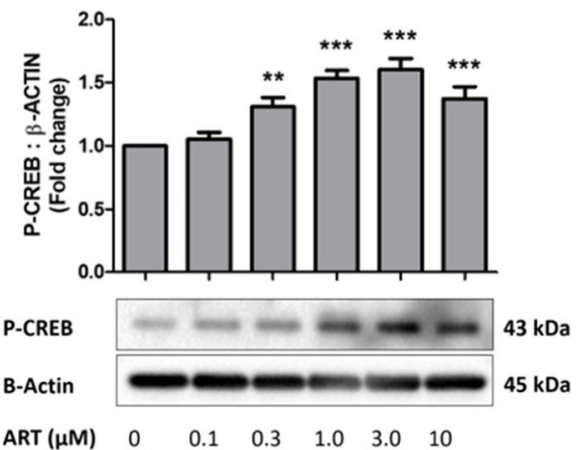

B
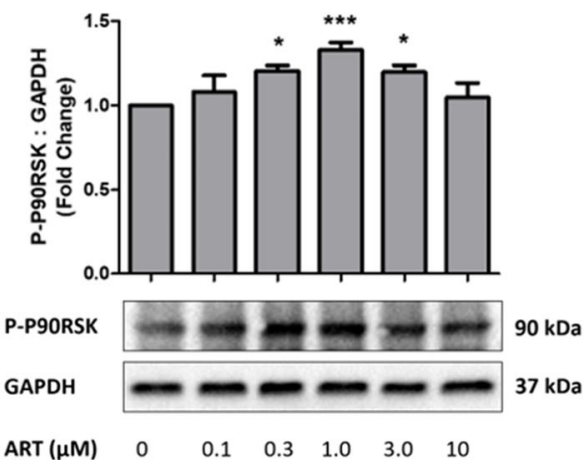

D

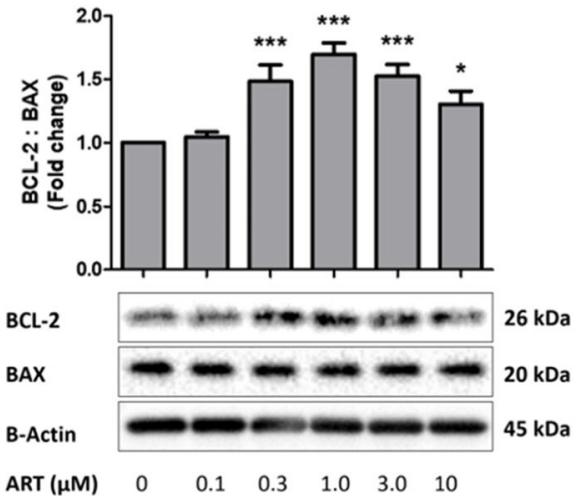

Fig. 8 Artemisinin activation of c-RAF (a), p90 RSK (b), CREB (c) phosphorylation and increased expression level of Bcl-2 (d). BMSCs were treated with various concentrations of artemisinin for $1 \mathrm{~h}$, and then, culture lysates were submitted for western blotting with respective antibodies $(n=3)$; ${ }^{*} p<0.05 ;{ }^{* *} p<0.01 ;{ }^{* *} p<0.005$ versus control group $(0 \mu \mathrm{M})$ 


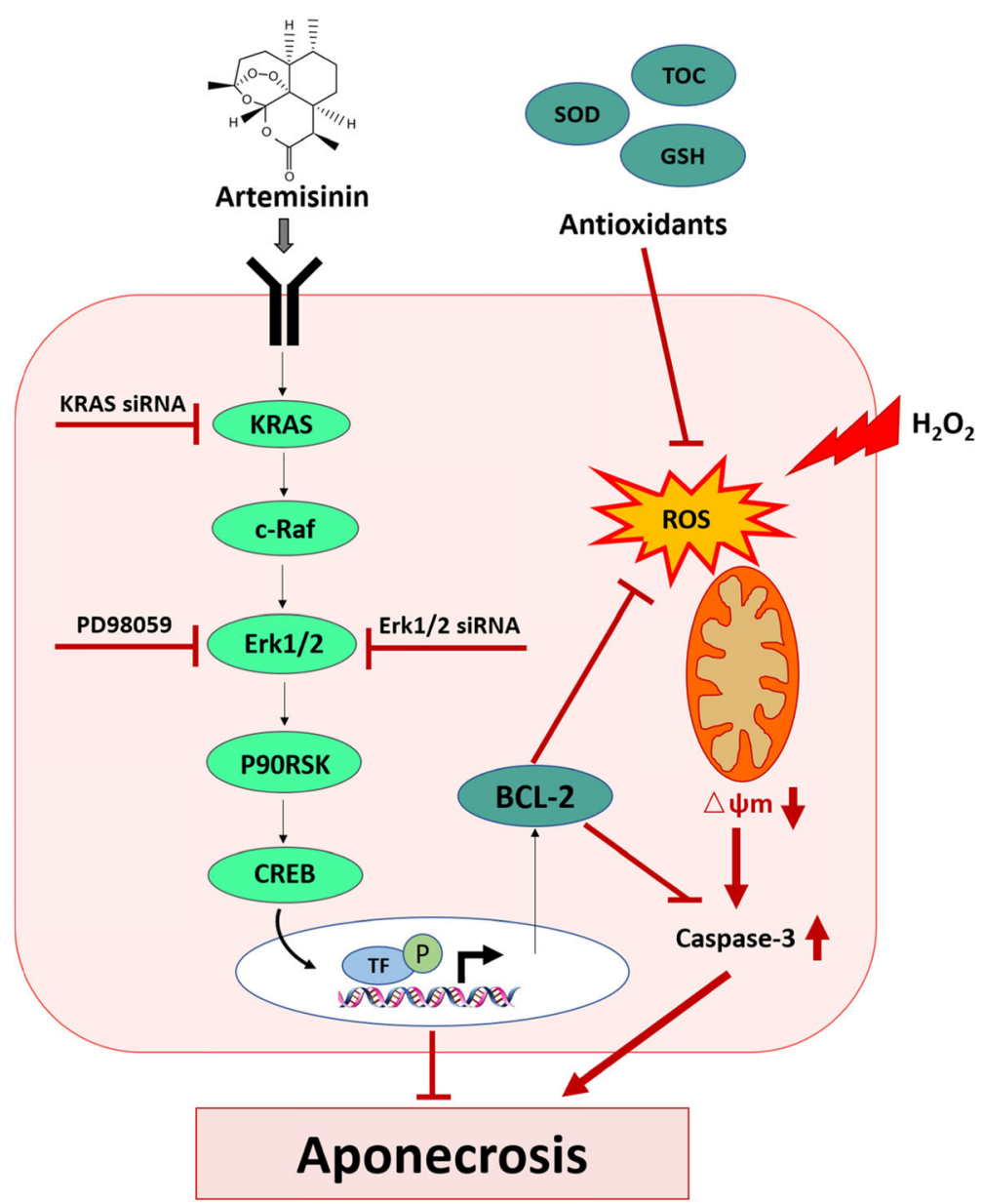

Fig. 9 Schematic representation of convergent pathways induced by artemisinin for cytoprotection of BMSCs towards $\mathrm{H}_{2} \mathrm{O}_{2}$-induced aponecrotic cell death. Black arrows - physiological pathways; red arrows - pathological pathways; red bars—inhibitory effect

p90 ${ }^{\mathrm{RSK}}$ and CREB indicating that the whole c-Raf, Erk1/2, p $90^{\mathrm{RSK}}$, CREB signaling pathway was activated by artemisinin. Accumulating evidence indicates that activated Erk1/2 phosphorylates $\mathrm{p} 90^{\mathrm{RSK}}$ and then triggers the phosphorylation of Bad, resulting in protection towards oxidative ischemic insults [86]. During cerebral ischemia, p-p $90^{\text {RSK }}$ phosphorylates the pro-apoptotic protein Bad and $\mathrm{p}$-Bad subsequently prevents Bad interaction with $\mathrm{Bcl}-2$ and inhibits pro-apoptotic protein Bax translocation to the mitochondria in the ischemic brain [87]. Erk1/2/ p $90^{\text {RSK }}$ play key roles in the activation of CREB in the ischemic tissue [88]. The transcription factor CREB plays important roles in the regulation of various cellular responses, like proliferation, and survival in a variety of cell types exposed to oxidative stress [89]. According to present results, we propose that artemisinin-induced activation of c-Raf-Erk1/2-p90 ${ }^{\text {RSK }}$-CREB-Bcl-2-related anti-apoptotic signaling might be involved in inhibition of caspase 3 activity and other cell death reactions, thereby conferring cytoprotection (Fig. 9).
In conclusion, we demonstrated that artemisinin pretreatment of BMSCs mediates a postconditioning benefit which protects them towards $\mathrm{H}_{2} \mathrm{O}_{2}$ oxidative stress injury. Primary cytoprotective mechanisms involve decrease ROS, activation of c-Raf-Erk1/2-p90 ${ }^{\mathrm{RSK}}$-CREB, increased expression of $\mathrm{Bcl}-2$, and attenuation of $\Psi \mathrm{m}$. The experiments presented, therefore, bridge a gap in knowledge between the transient benefits of BMSC transplantation seen in vivo and a novel therapeutic proposal of using artemisinin to achieve a more efficient protective capacity of transplanted BMSCs in ischemic tissues environment.

\section{Abbreviations}

ACTs: Artemisinin-based combination treatments; Akt: Proto-oncogene phosphoinositide 3-kinase-activated serine/threonine kinase; Bcl-2: B cell lymphoma 2 protein; BGP: Glycerol 2-phosphate; BMSCs: Bone marrowderived mesenchymal stem cells; BSA: Bovine serum albumin; CAT: Catalase; CREB: CAMP response element binding protein; DMSO: Dimethyl sulfoxide; Erk1/2: Extracellular-signal-regulated kinase 1/2; FACS: Fluorescence-activated cell sorting; FBS: Fetal bovine serum; GPx: Glutathione peroxidase;

$\mathrm{H}_{2} \mathrm{O}_{2}$ : Hydrogen peroxide; IBMX: 3-Isobutyl-1-methylxantine; MTT: 3-(4,5Dimethylthiazol-2-yl)-2, 5-diphenyltetrazolium bromide; NC: Nitrocellulose; OD: Optical density; p90 ${ }^{\text {rsk: }}$ p90 ribosomal s6 kinase; PI: Propidium iodide; 
ROS: Reactive oxygen species; SD: Standard deviation; SOD: Superoxide dismutase

\section{Acknowledgements}

PL holds the Jacob Gitlin Chair in Physiology and is affiliated with and supported by the David R. Bloom Center for Pharmacy and the Dr. Adolf and Klara Bretler Center for Research in Molecular Pharmacology and Therapeutics at the Hebrew University of Jerusalem, Israel.

\section{Authors' contributions}

JKF and $X Z$ performed the experiments and drafted the manuscript. SL, XGX, and HTW performed part of the experiments. PL revised the manuscript. $\mathrm{WHZ}$ conceived the hypothesis, designed the experiments, and revised the manuscript. All authors read and approved the final manuscript.

\section{Funding}

This research was supported by the National Natural Science Foundation of China (No. 31771128); the FHS Internal Collaboration Proposals 2017, MYRG2016-00052-FHS and MYRG2018-00134-FHS from University of Macau; and the Science and Technology Development Fund (FDCT) of Macao (016/ 2016/A1 and 0113/2018/A3).

\section{Availability of data and materials}

All data generated or analyzed during this study are included in this published article.

\section{Ethics approval and consent to participate}

All animal experiments were approved by the Animal Ethics Committee, University of Macau.

\section{Consent for publication}

Not applicable.

\section{Competing interests}

The authors declare that they have no competing interests.

\section{Author details}

${ }^{1}$ Centre of Reproduction, Development and Aging, Institute of Translational Medicine, Faculty of Health Sciences, University of Macau, Macau SAR, China. ${ }^{2}$ School of Pharmaceutical Sciences, Sothern Medical University, Guangzhou, China. ${ }^{3}$ School of Pharmacy Institute for Drug Research, Faculty of Medicine, The Hebrew University of Jerusalem, 91120 Jerusalem, Israel.

\section{Received: 3 April 2019 Revised: 2 August 2019}

Accepted: 16 September 2019 Published online: 26 October 2019

\section{References}

1. Samsonraj RM, et al. Concise review: multifaceted characterization of human mesenchymal stem cells for use in regenerative medicine. Stem Cells Transl Med. 2017;6(12):2173-85.

2. Miura $Y$, et al. Chimerism of bone marrow mesenchymal stem/stromal cells in allogeneic hematopoietic cell transplantation: is it clinically relevant? Chimerism. 2013;4(3):78-83.

3. Cashman TJ, Gouon-Evans V, Costa KD. Mesenchymal stem cells for cardiac therapy: practical challenges and potential mechanisms. Stem Cell Rev Rep. 2013;9(3):254-65.

4. Denu RA, Hematti P. Effects of oxidative stress on mesenchymal stem cell biology. Oxid Med Cell Longev. 2016:2989076.

5. Ludin A, et al. Reactive oxygen species regulate hematopoietic stem cell self-renewal, migration and development, as well as their bone marrow microenvironment. Antioxid Redox Signal. 2014;21(11):1605-19.

6. Ebert $\mathrm{R}$, et al. Selenium supplementation restores the antioxidative capacity and prevents cell damage in bone marrow stromal cells in vitro. Stem Cells. 2006;24(5):1226-35.

7. Dixit $P$, Katare $R$. Challenges in identifying the best source of stem cells for cardiac regeneration therapy. Stem Cell Res Ther. 2015;6(1):26.

8. Stabler CT, et al. Mesenchymal stem cells for therapeutic applications in pulmonary medicine. Br Med Bull. 2015;115(1):45-56.

9. Xing $Y$, et al. microRNA-378 promotes mesenchymal stem cell survival and vascularization under hypoxic-ischemic conditions in vitro. Stem Cell Res Ther. 2014;5(6):130.
10. Lahiani A, et al. Neuroprotective effects of bioactive compounds and MAPK pathway modulation in "ischemia" - stressed PC12 pheochromocytoma cells. Brain Sci. 2018;8(2):32.

11. Wei $H$, et al. Apoptosis of mesenchymal stem cells induced by hydrogen peroxide concerns both endoplasmic reticulum stress and mitochondrial death pathway through regulation of caspases, p38 and JNK. J Cell Biochem. 2010;111(4):967-78.

12. Rodrigues $M$, et al. Production of reactive oxygen species by multipotent stromal cells/mesenchymal stem cells upon exposure to fas ligand. Cell Transplant. 2012;21(10):2171-87.

13. Organization, W.H., The Africa malaria report 2003. 2003.

14. Mutabingwa TK. Artemisinin-based combination therapies (ACTs): best hope for malaria treatment but inaccessible to the needy! Acta Trop. 2005;95(3): 305-15.

15. Nosten F, White NJ. Artemisinin-based combination treatment of falciparum malaria. Am J Trop Med Hyg. 2007;77(6_Suppl):181-92.

16. Shi $C$, et al. Anti-inflammatory and immunoregulatory functions of artemisinin and its derivatives. Mediat Inflamm. 2015:435713.

17. Li T, et al. Anti-inflammatory and immunomodulatory mechanisms of artemisinin on contact hypersensitivity. Int Immunopharmacol. 2012;12(1): $144-50$.

18. Jin O, et al. A pilot study of the therapeutic efficacy and mechanism of artesunate in the MRL/Ipr murine model of systemic lupus erythematosus. Cell Mol Immunol. 2009;6(6):461.

19. Wen $Y$, et al. Artemisinin attenuates tubulointerstitial inflammation and fibrosis via the NF-kB/NLRP3 pathway in rats with 5/6 subtotal nephrectomy. J Cell Biochem. 2019;120(3):4291-300.

20. Cheng $C$, et al. Anti-allergic action of anti-malarial drug artesunate in experimental mast cell-mediated anaphylactic models. Allergy. 2013;68(2): 195-203.

21. Efferth T. Beyond malaria: the inhibition of viruses by artemisinin-type compounds. Biotechnol Adv. 2018;36(6):1730-7.

22. Appalasamy $S$, et al. Antimicrobial activity of artemisinin and precursor derived from in vitro plantlets of Artemisia annua L. Biomed Res Int. 2014: 215872.

23. Kim W-S, et al. Anti-inflammatory, antioxidant and antimicrobial effects of artemisinin extracts from Artemisia annua L. Korean J Physiol Pharmacol. 2015;19(1):21-7.

24. Goswami S, et al. Anti-helicobacter pylori potential of artemisinin and its derivatives. Antimicrob Agents Chemother. 2012;56(9):4594-607.

25. Singh NP, Lai HC. Artemisinin induces apoptosis in human cancer cells. Anticancer Res. 2004;24(4):2277-80.

26. Chaturvedi $\mathrm{D}$, et al. Artemisinin and its derivatives: a novel class of antimalarial and anti-cancer agents. Chem Soc Rev. 2010;39(2):435-54.

27. Lai $H$, Singh NP. Oral artemisinin prevents and delays the development of 7 , 12-dimethylbenz [a] anthracene (DMBA)-induced breast cancer in the rat. Cancer Lett. 2006;231(1):43-8.

28. Nakase I, et al. Transferrin receptor-dependent cytotoxicity of artemisinintransferrin conjugates on prostate cancer cells and induction of apoptosis. Cancer Lett. 2009;274(2):290-8.

29. Slezakova S, Ruda-Kucerova J. Anticancer activity of artemisinin and its derivatives. Anticancer Res. 2017;37(11):5995-6003.

30. Shimoke K, Chiba H. Nerve growth factor prevents 1-methyl-4-phenyl-1, 2, 3, 6-tetrahydropyridine-induced cell death via the Akt pathway by suppressing caspase-3-like activity using PC12 cells: relevance to therapeutical application for parkinson's disease. J Neurosci Res. 2001;63(5):402-9.

31. Gautam P, et al. Transcriptomic and proteomic profile of Aspergillus fumigatus on exposure to artemisinin. Mycopathologia. 2011;172(5):331.

32. Li J, et al. Artemisinins target GABAA receptor signaling and impair a cell identity. Cell. 2017;168(1-2):86-100 e15.

33. Guo $Y$, et al. Antidiabetic and antiobesity effects of artemether in $\mathrm{db} / \mathrm{db}$ mice. Biomed Res Int. 2018:8639523.

34. Chong $\mathrm{C}-\mathrm{M}$, Zheng $\mathrm{W}$. Artemisinin protects human retinal pigment epithelial cells from hydrogen peroxide-induced oxidative damage through activation of ERK/CREB signaling. Redox Biol. 2016;9:50-6.

35. Yan F, et al. Artemisinin protects retinal neuronal cells against oxidative stress and restores rat retinal physiological function from light exposed damage. ACS Chem Neurosci. 2017;8(8):1713-23.

36. Zeng $Z, X u J$, Zheng $W$. Artemisinin protects $P C 12$ cells against $\beta$-amyloidinduced apoptosis through activation of the ERK1/2 signaling pathway. Redox Biol. 2017;12:625-33. 
37. Zheng $W$, et al. Artemisinin conferred ERK mediated neuroprotection to PC12 cells and cortical neurons exposed to sodium nitroprusside-induced oxidative insult. Free Radic Biol Med. 2016;97:158-67.

38. Lu H, et al. Artesunate suppresses oxidative and inflammatory processes by activating Nrf2 and ROS-dependent p38 MAPK and protects against cerebral ischemia-reperfusion injury. Mol Med Rep. 2018;17(5):6639-46.

39. Chen $Y$, et al. MicroRNA-133 overexpression promotes the therapeutic efficacy of mesenchymal stem cells on acute myocardial infarction. Stem Cell Res Ther. 2017;8(1):268.

40. Gincberg $G$, et al. Nerve growth factor plays a role in the neurotherapeutic effect of a CD45+ pan-hematopoietic subpopulation derived from human umbilical cord blood in a traumatic brain injury model. Cytotherapy. 2018; 20(2):245-61.

41. Hanna H, Mir LM, Andre FM. In vitro osteoblastic differentiation of mesenchymal stem cells generates cell layers with distinct properties. Stem Cell Res Ther. 2018;9(1):203

42. Wang $\mathrm{H}$, et al. The role of Akt/FoxO3a in the protective effect of venlafaxine against corticosterone-induced cell death in PC12 cells. Psychopharmacology. 2013;228(1):129-41.

43. Felzen $V$, et al. Estrogen receptor a regulates non-canonical autophagy that provides stress resistance to neuroblastoma and breast cancer cells and involves BAG3 function. Cell Death Dis. 2015;6(7):e1812.

44. Chan FK-M, Moriwaki K, De Rosa MJ. Detection of Necrosis by Release of Lactate Dehydrogenase Activity. In: Snow AL, Lenardo MJ, editors. Immune Homeostasis. New York: Humana Press; 2013. p. 65-70.

45. Arien-Zakay $\mathrm{H}$, et al. Neuroprotection by cord blood neural progenitors involves antioxidants, neurotrophic and angiogenic factors. Exp Neurol. 2009;216(1):83-94

46. Wen $\mathrm{Q}$, et al. Characterization of intracellular translocation of Forkhead transcription factor O (FoxO) members induced by NGF in PC12 cells. Neurosci Lett. 2011;498(1):31-6.

47. Michl J, et al. FANCD2 limits replication stress and genome instability in cells lacking BRCA2. Nat Struct Mol Biol. 2016;23(8):755.

48. Chen P-C, et al. Nrf2-mediated neuroprotection in the MPTP mouse mode of Parkinson's disease: critical role for the astrocyte. Proc Natl Acad Sci. 2009; 106(8):2933-8.

49. Wu Y, et al. ROCK inhibitor Y27632 promotes proliferation and diminishes apoptosis of marmoset induced pluripotent stem cells by suppressing expression and activity of caspase 3. Theriogenology. 2016;85(2):302-14.

50. Zheng W-H, Quirion R. Glutamate acting on N-methyl-D-aspartate receptors attenuates insulin-like growth factor-1 receptor tyrosine phosphorylation and its survival signaling properties in rat hippocampal neurons. J Biol Chem. 2009;284(2):855-61.

51. Kim KS, et al. Small intestine submucosa sponge for in vivo support of tissue-engineered bone formation in the presence of rat bone marrow stem cells. Biomaterials. 2010;31(6):1104-13.

52. Li X, Zhang Y, Qi G. Evaluation of isolation methods and culture conditions for rat bone marrow mesenchymal stem cells. Cytotechnology. 2013;65(3):323-34.

53. Kern $\mathrm{S}$, et al. Comparative analysis of mesenchymal stem cells from bone marrow, umbilical cord blood, or adipose tissue. Stem Cells. 2006;24(5): 1294-301.

54. Zhao H, et al. Transplantation of cerebral dopamine neurotrophic factor transducted BMSCs in contusion spinal cord injury of rats: promotion of nerve regeneration by alleviating neuroinflammation. Mol Neurobiol. 2016; 53(1):187-99.

55. Brand MD, et al. Mitochondrial superoxide and aging: uncoupling-protein activity and superoxide production. In: Biochemical Society Symposia. 2004. London: Portland on behalf of The Biochemical Society; 1999.

56. Dixon SJ, Stockwell BR. The role of iron and reactive oxygen species in cell death. Nat Chem Biol. 2014;10(1):9-17.

57. Zorov DB, Juhaszova M, Sollott SJ. Mitochondrial reactive oxygen species (ROS) and ROS-induced ROS release. Physiol Rev. 2014;94(3):909-50.

58. Zeng $Z, X u J$, Zheng $W$. Artemisinin protects PC12 cells against $\beta$-amyloidinduced apoptosis through activation of the ERK1/2 signaling pathway. Redox Biol. 2017;12:625-33.

59. Sauer $H$, Wartenberg $M$, Hescheler J. Reactive oxygen species as intracellular messengers during cell growth and differentiation. Cell Physiol Biochem. 2001;11(4):173-86.

60. Le Belle JE, et al. Proliferative neural stem cells have high endogenous ROS levels that regulate self-renewal and neurogenesis in a PI3K/Akt-dependant manner. Cell Stem Cell. 2011;8(1):59-71.
61. Chiarugi P, Fiaschi T. Redox signalling in anchorage-dependent cell growth. Cell Signal. 2007;19(4):672-82.

62. Ito $K$, et al. Reactive oxygen species act through p38 MAPK to limit the lifespan of hematopoietic stem cells. Nat Med. 2006;12(4):446-51.

63. Brandl $A$, et al. Oxidative stress induces senescence in human mesenchymal stem cells. Exp Cell Res. 2011;317(11):1541-7.

64. Kim M, et al. Age-related alterations in mesenchymal stem cells related to shift in differentiation from osteogenic to adipogenic potential: implication to age-associated bone diseases and defects. Mech Ageing Dev. 2012; 133(5):215-25.

65. Green DR, Kroemer G. The pathophysiology of mitochondrial cell death. Science. 2004;305(5684):626-9.

66. Zhang W, Liu HT. MAPK signal pathways in the regulation of cell proliferation in mammalian cells. Cell Res. 2002;12(1):9.

67. Sun Y, et al. Signaling pathway of MAPKJERK in cell proliferation, differentiation, migration, senescence and apoptosis. J Recept Signal Transduct. 2015;35(6):600-4.

68. Miloso $\mathrm{M}$, et al. MAPKs as mediators of cell fate determination: an approach to neurodegenerative diseases. Curr Med Chem. 2008;15(6):538-48.

69. Wu Q, et al. The antioxidant, immunomodulatory, and anti-inflammatory activities of Spirulina: an overview. Arch Toxicol. 2016;90(8):1817-40.

70. Shonai T, et al. MEK/ERK pathway protects ionizing radiation-induced loss of mitochondrial membrane potential and cell death in lymphocytic leukemia cells. Cell Death Differ. 2002;9(9):963.

71. Oh Y-T, et al. Oncogenic Ras and B-Raf proteins positively regulate death receptor 5 expression through co-activation of ERK and JNK signaling. J Biol Chem. 2012;287(1):257-67.

72. Wang $\mathrm{H}$, et al. The nerve growth factor signaling and its potential as therapeutic target for glaucoma. Biomed Res Int. 2014:759473.

73. Emily $\mathrm{H}-\mathrm{YC}$, et al. BCL-2, BCL-XL sequester $\mathrm{BH} 3$ domain-only molecules preventing BAX-and BAK-mediated mitochondrial apoptosis. Mol Cell. 2001; 8(3):705-11.

74. Cheng C-Y, et al. Ferulic acid administered at various time points protects against cerebral infarction by activating p38 MAPK/p90RSK/CREB/BCl-2 antiapoptotic signaling in the subacute phase of cerebral ischemia-reperfusion injury in rats. PLoS One. 2016;11(5):e0155748.

75. Yu ACH, et al. Cycloheximide and actinomycin D delay death and affect bcl2, bax, and Ice gene expression in astrocytes under in vitro ischemia. J Neurosci Res. 2003;74(2):318-25.

76. Kanda N, Watanabe S. 17ß-estradiol inhibits oxidative stress-induced apoptosis in keratinocytes by promoting $\mathrm{BCl}-2$ expression. J Investig Dermatol. 2003;121(6):1500-9.

77. Susnow N, Zeng L, Margineantu D, Hockenbery DM. Bcl-2 family proteins as regulators of oxidative stress. Semin Cancer Biol. 2009;19:42-9.

78. Czabotar PE, et al. Control of apoptosis by the BCL-2 protein family: implications for physiology and therapy. Nat Rev Mol Cell Biol. 2014;15(1):49.

79. Chipuk JE, et al. The BCL-2 family reunion. Mol Cell. 2010;37(3):299-310.

80. Aikawa $\mathrm{R}$, et al. Insulin prevents cardiomyocytes from oxidative stressinduced apoptosis through activation of PI3 kinase/Akt. Circulation. 2000; 102(23):2873-9.

81. Koh S-H, et al. Epigallocatechin gallate protects nerve growth factor differentiated PC12 cells from oxidative-radical-stress-induced apoptosis through its effect on phosphoinositide 3-kinase/Akt and glycogen synthase kinase-3. Mol Brain Res. 2003;118(1-2):72-81.

82. Martín MÁ, et al. Cocoa flavonoids up-regulate antioxidant enzyme activity via the ERK1/2 pathway to protect against oxidative stress-induced apoptosis in HepG2 cells. J Nutr Biochem. 2010;21(3):196-205.

83. Borrás $C$, et al. 17ß-oestradiol up-regulates longevity-related, antioxidant enzyme expression via the ERK1 and ERK2 [MAPK]/NFKB cascade. Aging Cell. 2005;4(3):113-8.

84. Liang D, et al. ZnT7 can protect MC3T3-E1 cells from oxidative stressinduced apoptosis via PI3K/Akt and MAPK/ERK signaling pathways. Cell Signal. 2013;25(5):1126-35.

85. Mudalagiri $\mathrm{N}$, et al. Erythropoietin protects the human myocardium against hypoxia/reoxygenation injury via phosphatidylinositol-3 kinase and ERK1/2 activation. Br J Pharmacol. 2008;153(1):50-6.

86. Cheng $C Y$, et al. Electroacupuncture-like stimulation at Baihui and Dazhui acupoints exerts neuroprotective effects through activation of the brainderived neurotrophic factor-mediated MEK1/2/ERK1/2/p90RSK/bad signaling pathway in mild transient focal cerebral ischemia in rats. BMC Complement Altern Med. 2014;14(1):92. 
87. Koh P-O. Melatonin attenuates the cerebral ischemic injury via the MEK ERK/p90RSK/bad signaling cascade. J Vet Med Sci. 2008;70(11):1219-23.

88. Liu C, et al. Clematichinenoside serves as a neuroprotective agent against ischemic stroke: the synergistic action of ERK1/2 and CPKC pathways. Front Cell Neurosci. 2016;9:517.

89. Sugiura S, et al. CRE-mediated gene transcription in the peri-infarct area after focal cerebral ischemia in mice. J Neurosci Res. 2004;75(3):401-7.

\section{Publisher's Note}

Springer Nature remains neutral with regard to jurisdictional claims in published maps and institutional affiliations.

Ready to submit your research? Choose BMC and benefit from:

- fast, convenient online submission

- thorough peer review by experienced researchers in your field

- rapid publication on acceptance

- support for research data, including large and complex data types

- gold Open Access which fosters wider collaboration and increased citations

- maximum visibility for your research: over $100 \mathrm{M}$ website views per year

At $\mathrm{BMC}$, research is always in progress.

Learn more biomedcentral.com/submissions 